\title{
AN EXAMINATION OF MUSICAL INSTRUMENT PRACTICE AMONG COLLEGIATE MUSICIANS
}

\begin{tabular}{c} 
A Dissertation \\
presented to \\
the Faculty of the Graduate School \\
at the University of Missouri-Columbia \\
In Partial Fulfillment \\
of the Requirements for the Degree \\
Doctor of Philosophy \\
Dr. Brian Silvey, Dissertation Supervisor \\
YUE LIU \\
\hline
\end{tabular}

MAY 2021 
The undersigned, appointed by the dean of the Graduate School, have examined the dissertation entitled

\section{AN EXAMINATION OF MUSICAL INSTRUMENT PRACTICE AMONG COLLEGIATE MUSICIANS}

presented by Yue Liu,

a candidate for the degree of doctor of philosophy,

and hereby certify that, in their opinion, it is worthy of acceptance.

Dr. Brian Silvey

Dr. Wendy Sims

Dr. Brandon Boyd

Dr. Judith Mabary 


\section{ACKNOWLEDGEMENT}

Thank you to Dr. Brian Silvey for providing guidance throughout my dissertation. I appreciate your time, efforts, and supports to help me become a better researcher and music teacher educator. I will forever cherish our meetings and conversations.

Thank you to Dr. Wendy Sims for your supports across my doctoral journey. Your thoughtful words made me feel warm. Your positive feedback encouraged me to believe that I can do better than I thought. Your passion and dedication to music education always inspire me.

I would also like to thank my committee members, Dr. Brandon Boyd and Dr. Judith Mabary, for their support and encouragement. I am lucky to have you both as mentors. You both made this dissertation possible.

In addition, I would like to thank my peers and colleagues who helped me review my dissertation and provided constructive suggestions. Your professional feedback encouraged me to think deeply and critically while I was reviewing my final manuscript.

I am grateful to my friend, Jason Han, who provided interesting discussions as well as happy distractions to rest my mind outside of my research. I am so fortunate to have met you.

Finally, I would like to thank my parents' constant care. I could not achieve my dream pursuing my $\mathrm{PhD}$ in the United States without your loving support. 


\section{TABLE OF CONTENTS}

ACKNOWLEDGEMENT ........................................................................................ ii

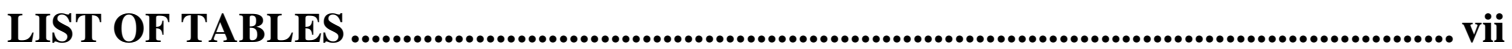

ABSTRACT ...................................................................................................................................... viii

Chapter One ......................................................................................................................................... 1

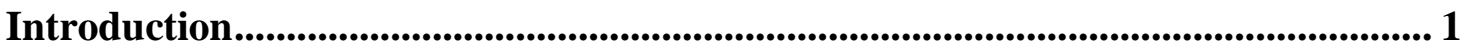

Problem and Purpose ................................................................................................................... 5

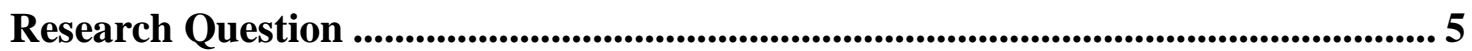

Research Plan .................................................................................................................................. 6

Importance of the Study ............................................................................................................ 8

Definitions.......................................................................................................................................... 9

Chapter Two................................................................................................................................. 10

Strategies and Influential Factors for Musical Instrument Practice: A Review of

Literature................................................................................................................................ 10

Deliberate Practice......................................................................................................................... 11

Deliberate Practice in Instrumental Learning ................................................................. 12

Instrumental Learning and Practice..................................................................................... 14

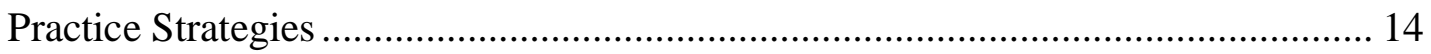

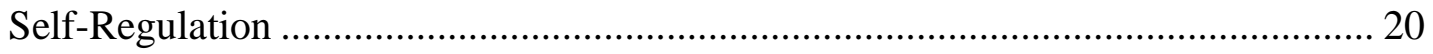

Practice Attitudes and Beliefs .................................................................... 22 


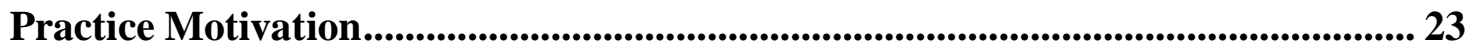

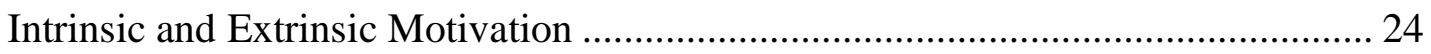

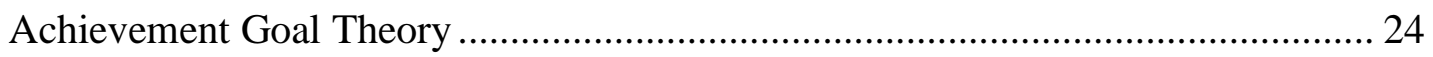

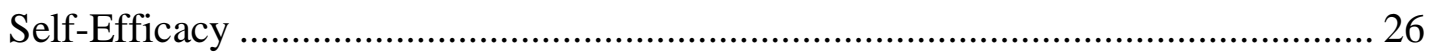

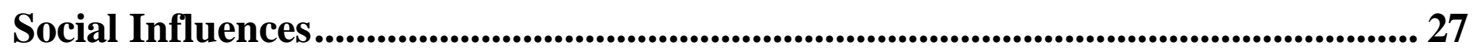

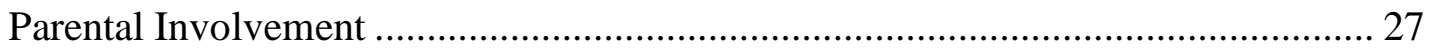

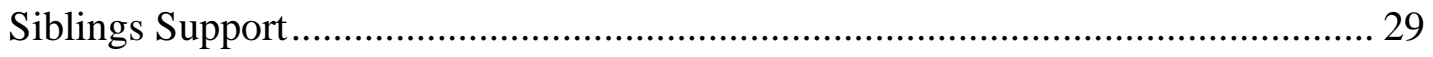

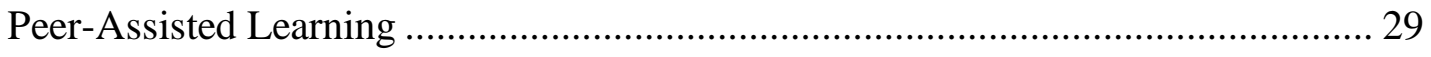

Conclusion ......................................................................................................................................... 30

Chapter Three ........................................................................................................................................ 32

Practice Habits and Motivation: A Qualitative Descriptive Study of Graduate

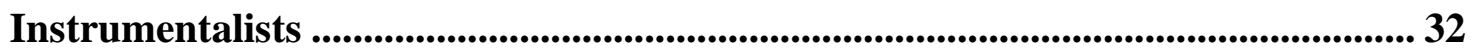

Method .................................................................................................................................................. 37

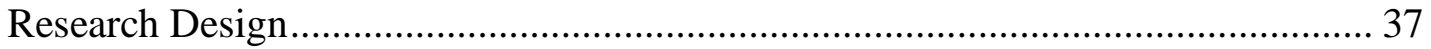

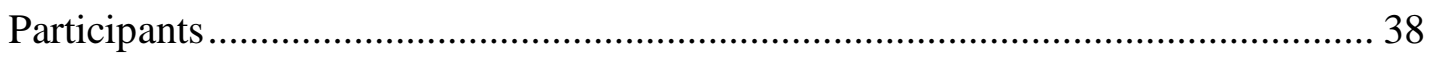

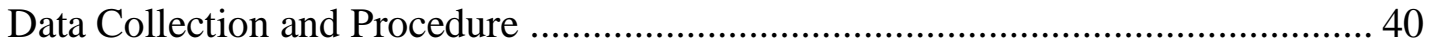

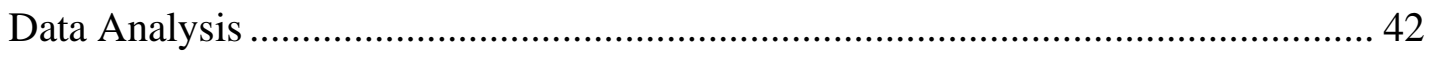

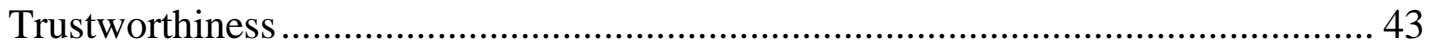

Findings and Discussion ................................................................................................... 45

Theme One: Task-Oriented Practice Routines............................................................. 45

Theme Two: Solution-Oriented Approaches .............................................................. 48

Theme Three: Mixed Motivations …………………………………................... 51 


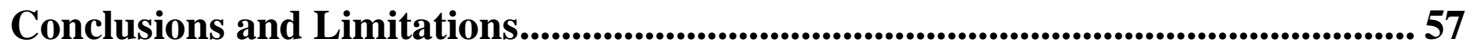

Chapter Four ............................................................................................................................................. 61

Collegiate Instrumentalists' Applications of Practice Strategies and Practice

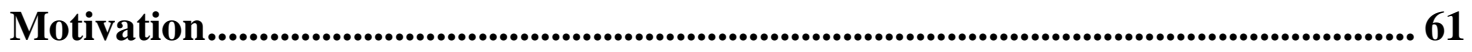

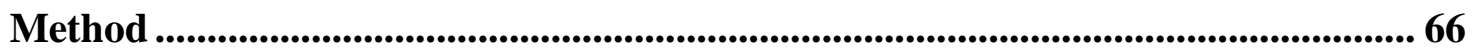

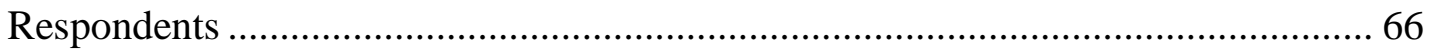

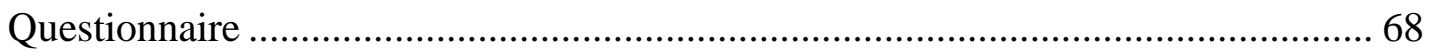

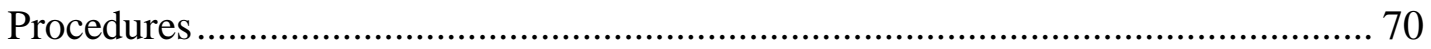

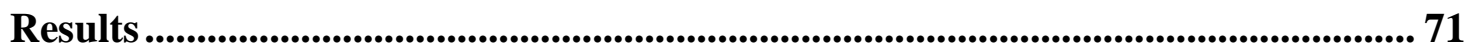

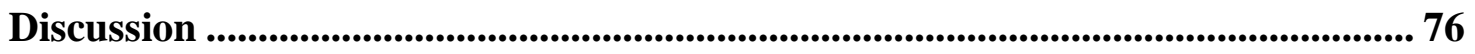

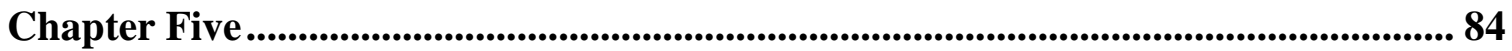

Summary and Conclusions ........................................................................................... 84

Research Questions and Method ................................................................... 85

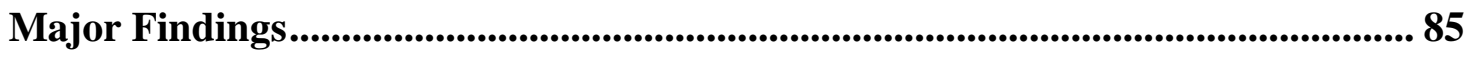

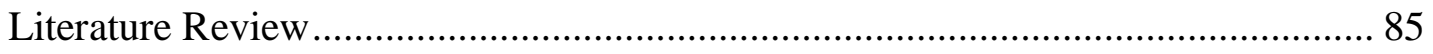

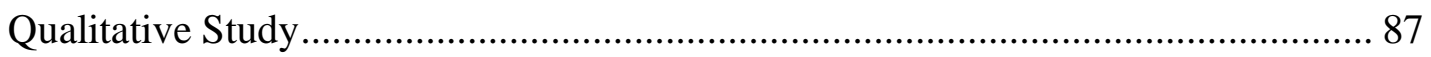

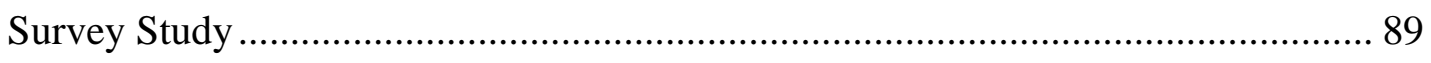

Suggestions for Studio Instructors ........................................................................... 91

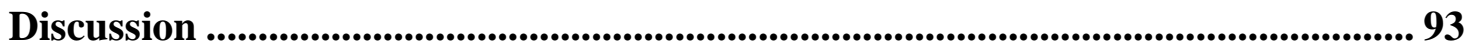

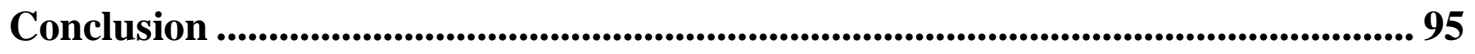




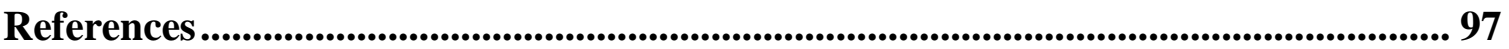

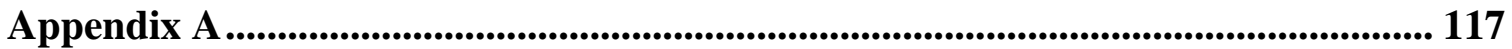

Appendix B .................................................................................................................... 119

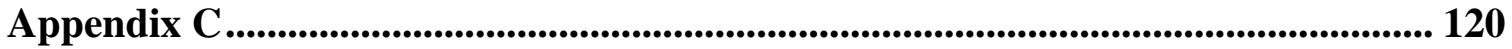

Appendix D.............................................................................................................. 122

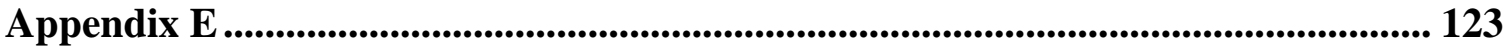

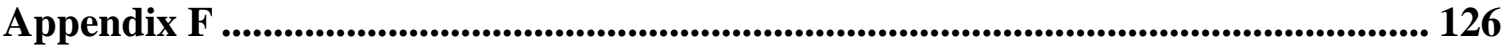

Appendix G....................................................................................................................... 128

Appendix H........................................................................................................................ 129

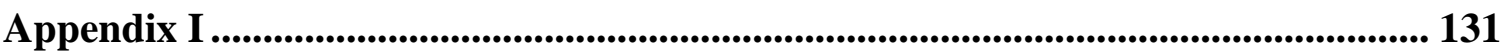

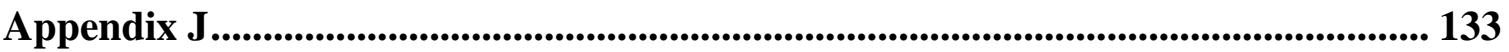

Appendix K......................................................................................................................... 134

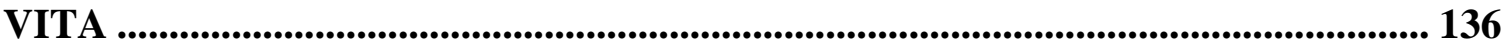




\section{LIST OF TABLES}

Table 1 Descriptions of Participants

Table 2 Responses to the Practice Motivation Subscales in Order from Highest to Lowest

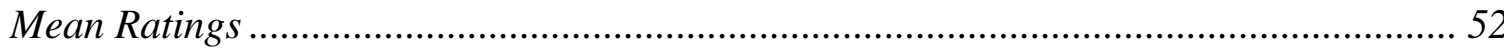

Table 3 Means and Standard Deviations of Respondents' Reported Actual and Intended

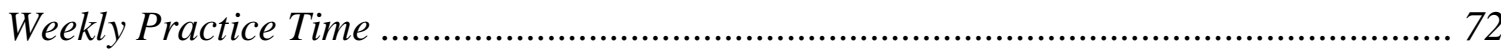

Table 4 Means and Standard Deviations of Respondents' Applied Practice Strategies

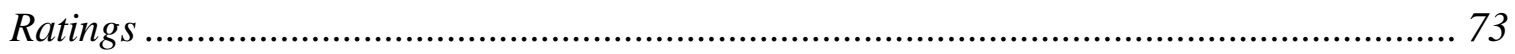

Table 5 Means and Standard Deviations of Respondents' Practice Motivation by

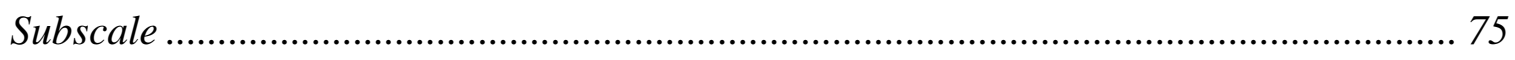

Table 6 Spearman's Rho Correlations for Respondents' Practice Motivation, Practice

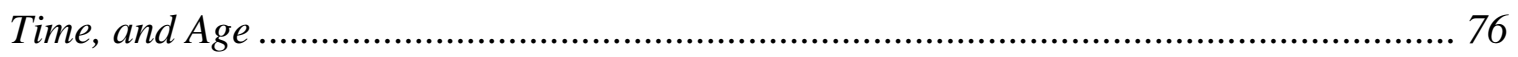




\title{
AN EXAMINATION OF MUSICAL INSTRUMENT PRACTICE AMONG COLLEGIATE MUSICIANS
}

\author{
Yue Liu \\ Dr. Brian Silvey, Dissertation Supervisor
}

\begin{abstract}
This dissertation consists of three projects that were designed to investigate collegiate instrumentalists' practice habits and motivation orientations. The first investigation was a review of the literature about instrumental practice strategies, motivation orientations, and social factors influencing music practice. The second investigation was a qualitative descriptive study of four graduate instrumentalists' practice organization, application of practice strategies, and motivation orientations. Emergent themes included (a) task-oriented practice routines, (b) solution-oriented approaches, (c) mixed motivations, and (d) external challenges. The third investigation was a survey study of collegiate instrumentalists' application of practice strategies and their motivation orientations to practice. Results indicated that pianists spent more time in practice than percussionists, brass, other instrumentalists (e.g., organ), woodwind, and string players, respectively. Collegiate instrumentalists used systematic practice strategies most frequently, followed by error correction techniques, using a metronome and listening to recordings, concentration control, analytic strategies, and the organization of practice sessions. In addition, collegiate instrumentalists were more motivated by intrinsic factors than extrinsic factors. Weekly practice hours were negatively correlated with Extrinsic Motivation: Avoid Failure, but positively correlated with Intrinsic Motivation: Growth. Taken together, results from these projects indicated that collegiate
\end{abstract}


instrumentalists should (a) develop and strengthen self-regulation skills, (b) arrange practice time based on individual schedules, and (c) cope with challenges through discussing potential solutions with peers and instrumental instructors. 


\section{Chapter One}

\section{Introduction}

Practice is critical to musicians' expertise development. As a multi-faceted activity, music practice involves improving technical skills, developing musical interpretation, playing from memory, and overcoming performance stress (Hallam, 1997). Practice "allows musicians to reinforce knowledge learned from instructors, engage in self-discovery, and develop habits of mind" (Austin \& Berg, 2006, p. 535). Specifically, the use of effective practice strategies (Graaff, 2014; Hallam et al., 2012), time spent in practice (Ericsson et al., 1993; Jørgensen, 2004), motivation orientations (Hallam, 2002; Schmidt, 2005; Tan \& Miksza, 2019), and social influences (Petersen, 2018) may affect musicians' performance achievement. Given the complexity of music performance, effectively combining these components while practicing plays an important role in musicians' expertise and their career development.

The application of effective practice strategies affects musicians' development positively. Jørgensen (2004) suggested that practice strategies are thoughts and behaviors that are used to affect "musicians' motivational or affective state, or the way in which they select, organize, integrate, and rehearse new knowledge and skills" (p. 85). The most common practice strategy adopted by instrumentalists across all levels is repetition. Beginners were inclined to play through pieces or play the same measures repeatedly (McPherson \& Renwick, 2001), whereas professional musicians repeated small sections accompanied by alternating tempos to achieve performance goals (Graaff, 2014). Additionally, musicians who practice effectively have been shown to apply analytic strategies (Hamlin, 2014; Rohwer \& Polk, 2006), mental practice (Fine et al., 2015; 
Gabrielsson, 1999), listening to recordings and using a metronome (Geringer et al., 2015; Miksza \& Tan, 2015), and error detection and correction techniques (Nielsen, 1997; Pitts \& Davidson, 2000). Although previous research mostly involved middle and high school musicians' practice habits (Austin \& Berg, 2006; Christensen, 2010; Hallam et al., 2012; Hamlin, 2014; Miksza, 2007; Pike, 2017), few researchers have examined collegiate instrumentalists' practice behaviors (Araújo, 2016; Byo \& Cassidy, 2008). It appears necessary to investigate practice strategies used by collegiate musicians, which may help instructors to provide additional suggestions that may be overlooked by their students. Further examinations could also inform collegiate instrumentalists' practice habits and encourage them to optimize their applications of practice strategies, contributing to making progress on instruments and sufficiently preparing for future teaching and performances.

Instrumentalists spend more hours in practice as expertise develops. Because advanced musicians use more complicated and difficult technical exercises and pieces during practice compared to beginners, longer practice time is needed to accomplish increasingly difficult tasks (Hallam et al., 2012). Similarly, researchers indicated that time spent in deliberate practice, which refers to "a well-defined task with an appropriate difficulty level for the particular individual, informative feedback, and opportunities for repetition and corrections of errors" (Ericsson, 1996, p. 21) could predict the skill level of musicians (Ericsson et al., 1993) and their performance achievement (Bonneville-Roussy et al., 2011). Collegiate instrumentalists were encouraged to engage in around 20 to 25 hours per week of deliberate practice to develop technical skills and refine performance (Jørgensen, 2004). However, in another study, collegiate musicians reported that their 
practice time was approximately 10 hours per week, whereas instructors expected an average of 14.5 hours' worth of practice (Kostka, 2002). Investigating collegiate instrumentalists' time spent in practice can provide a better understanding of how they organize practice sessions as well as set and achieve performance goals.

Applying self-regulation skills may help achieve musicians' goals and improve practice efficiency. Common self-regulation skills include goal setting, metacognitive thinking, planning and time management, self-evaluation, actively searching for resources, and help-seeking (Araújo, 2016; Austin \& Berg, 2006; Hallam, 2001b; Miksza, 2006a). Araújo (2016) wrote that self-regulation through personal resources, including knowing individual weaknesses and strengths and the nature of using strategies, are relevant to practice efficiency. Instrumentalists who perceived themselves to be selfregulated and efficient in practice were more likely to accomplish their goals, demonstrate metacognition and self-awareness, and experience flow while practicing (Miksza \& Tan, 2015). However, short attention spans and tiredness made it difficult for teenaged pianists to focus and engage in deliberate practice, which hindered setting goals and their ability to identify mistakes during practice (Pike, 2017). These results suggest that self-regulation abilities affect practice efficiency and the organization of practice.

Practice motivation has been found to explain approximately $20 \%$ of the variance in performance achievement and related behaviors (Asmus, 1994). Although collegiate instrumentalists were more inclined to exhibit intrinsic motivation than extrinsic motivation in ensemble learning contexts (Diaz, 2010), professional musicians exhibited extrinsic, intrinsic, and mixed motivation orientations toward instrumental practice (Hallam, 1995). Moreover, self-efficacy was positively related to music aptitude scores 
and performance quality (McCormick \& McPherson, 2003; Zelenak, 2014). Achievement goal theory, which refers to a psychological theory of intrinsic motivation focusing on how beliefs and cognition direct us toward achievement or success, affected the development of musical creativity, emotional states, and performance achievement (Tan \& Miksza, 2019; Wang et al., 2018). According to these findings, investigating collegiate instrumentalists' practice motivation enables instructors to understand their students' concerns and perspectives toward practice and encourages instructors to provide specific and helpful feedback to arouse students' desire to practice and improve performance achievement.

Social factors (e.g., parents, peers, contexts) may influence instrumental learning experience and efficiency. Parental involvement can help children develop self-regulation skills (Upitis et al., 2017) and promote practice motivation and cognition of musical elements such as rhythm and tone (Zdzinski, 1996). Peer-assisted learning was regarded as a way to cultivate a sense of confidence and ownership (Johnson, 2015; Webb, 2015) and a chance to improve the tutor's expertise because teaching helps consolidate existing knowledge (Petersen, 2018). Additionally, the outbreak of the Covid-19 pandemic has resulted in some schools moving to remote learning since spring 2020. Music teachers encountered unprecedented challenges such as organizing virtual musical activities, engaging students in online lessons, and making available instruments and technologies (Hash, 2021). A qualitative investigation concerning instrumentalists' practice habits and motivation during the pandemic may provide information for instructors and administrators about how social change affects instrumentalists' practice organization, efficiency, and motivation. 


\section{Problem and Purpose}

There have been many investigations related to practice habits and behaviors of middle and high school musicians (Austin \& Berg, 2006; Christensen, 2010; Hamlin, 2014; Miksza, 2007; Miksza et al., 2012; Petersen, 2018; Prichard, 2017) and expert musicians who achieved international recognition (Graaff, 2014; Harnum, 2013). However, few studies involved collegiate musicians (Araújo, 2016; Byo \& Cassidy, 2008) and their practice motivation orientations (Nielsen, 2008; Tan \& Miksza, 2019). Furthermore, there has been scant evidence about the relationship between time spent in practice and motivation among collegiate musicians (McCormick \& McPherson, 2003; Miksza, 2010). Considering that these factors are associated with achieving expertise, further study of collegiate instrumentalists' application of practice strategies and their motivation orientations toward music practice seems warranted. These investigations would allow instructors to know their students' practice habits and challenges, thus providing targeted instructions for developing students' expertise. Moreover, collegiate instrumentalists could refer the results of investigations to their practice habits, which would encourage them to assess and reflect on their practice sessions and further enrich technical skills.

\section{Research Question}

The following primary research questions guided my investigation: (1) What are the practice habits (i.e., practice time, strategies, organization) of collegiate instrumentalists? (2) What practice motivation orientations do collegiate instrumentalists possess? 


\section{Research Plan}

To begin my exploration, I reviewed extant literature about deliberate practice, instrumental practice strategies, motivation orientations, and social factors relating to practice such as family involvement and peer-learning. By synthesizing these previous studies, I identified common practice strategies adopted by instrumentalists across all levels from beginners to professionals, and the effect of motivation orientations on instrumental learning. Then, in two separate studies, I explored practice time, practice strategies, the organization of practice routines, and motivation orientations among collegiate instrumentalists. Therefore, this dissertation consists of three investigations designed to examine collegiate instrumentalists' practice habits and motivation orientations.

The first investigation was a review of the literature about instrumental practice strategies, motivation orientations, and social factors influencing music practice. Because research findings indicated that performance achievement was related to practice time and the application of practice strategies (Duke et al., 2009; Ericsson et al., 1993; McPherson, 2005), investigating collegiate instrumentalists' use of practice time and what common practice strategies were employed seemed warranted. These data can provide specific information to instructors about their students' practice habits. Attention also was given to motivation orientations, including intrinsic and extrinsic motivation, self-efficacy, and achievement goal theory, which may affect instrumentalists' performance achievement. Additionally, the effects of family involvement and peerassisted learning on instrumental learning were also discussed. This review of literature 
was designed to identify practice habits and motivation orientations that can affect instrumentalists' expertise development.

The second investigation was a qualitative descriptive study regarding four graduate instrumentalists' organization of practice sessions, adopted practice strategies, and factors motivating or hindering their practice. Although researchers indicated that having structured practice routines and plans contribute to practice efficiency (Barry, 1992; Nielsen, 2004), static or identical routines may bring negative outcomes (Byo \& Cassidy, 2008). Few researchers have investigated graduate instrumentalists' practice routines and adopted practice strategies. Results may inform instrumental instructors about how their students organize practice routines and help them identify ways to assist their students to become more effective practicers. Moreover, previous investigations examined collegiate musicians, including both undergraduate and graduate students (Diaz, 2010), and professional musicians' practice motivation (Hallam, 1995). My study focused on graduate instrumentalists majoring in music performance. Findings may increase our understanding about factors that can motivate or hinder graduate instrumentalists' practice motivation. It would also allow us to learn how graduate instrumentalists organize their practice routines and set goals for practice sessions, especially considering that they often participate in several music-related activities and practice multiple musical pieces at the same time.

The third investigation was a survey study designed to examine collegiate instrumentalists' applications of practice strategies and their motivation to practice. Although researchers have studied practice strategies adopted by pre-college musicians (Austin \& Berg, 2006; Christensen, 2010; Hallam et al., 2012; Hamlin, 2014; Miksza et 
al., 2012; Prichard, 2017; Yoo, 2020) and professional musicians who achieved international recognition (Graaff, 2014; Harnum, 2013), there have been few studies involving collegiate musicians' usage and frequency of practice strategies and the relationship between time spent in practice and motivation (Araújo, 2016). Understanding these aspects of their practice could inform instrumental instructors' teaching practices and help refine their students' musicianship.

In the final chapter of my dissertation, I present a synthesis of the findings of my three studies, discuss the implications of my results, and provide ideas for future research. Suggestions for studio instructors and instrumentalists are presented.

\section{Importance of the Study}

This dissertation will provide insights into what practice strategies are adopted by collegiate instrumentalists and how these strategies are applied during practice.

Examining collegiate instrumentalists' usage of practice strategies could provide information to instructors on what technical skills may be overlooked by their students, so they can interpret, emphasize, and model during lessons. Understanding how graduate instrumentalists organize their practice routines could help other instrumentalists when designing practice routines applicable to their individual schedules. Further investigations concerning graduate instrumentalists' practice motivation may help instrumental instructors learn reasons that motivated and hindered their practice such that instructors might consider individualized approaches to help increase their students' motivation to practice. 


\section{Definitions}

- Collegiate Instrumentalists: Instrumentalists (undergraduate or graduate) who are music majors and enrolled in concert band or orchestra at higher education institutions.

- Graduate Instrumentalists: Instrumentalists who were master's students in music performance and enrolled in studio lessons at higher education institutions.

- Extrinsic Motivation: Behavior that is driven by external rewards or factors.

- Intrinsic Motivation: Behavior that is driven by internal factors.

- Practice Strategies: Thoughts and behaviors during practice through which musicians select, organize, integrate, and rehearse new knowledge and skills.

- Practice Routine: A regular course or procedure that may be repeated by instrumentalists while practicing.

- Self-Regulated Learning: A learning process that involves one's own metacognitively, motivationally, and behaviorally active participation. 


\section{Chapter Two}

\section{Strategies and Influential Factors for Musical Instrument Practice: A Review of}

\section{Literature}

Practice is central to attaining expertise. In an effort to improve musicianship, instrumentalists have adopted various practice strategies including deliberate practice (Ericsson, 1996; Ericsson et al., 1993), analytic strategies (Hamlin, 2014; Rohwer \& Polk, 2006), error detection and correction techniques (Nielsen, 1997; Pitts \& Davidson, 2000), mental practice (Fine et al., 2015; Gabrielsson, 1999), and use of practice tools (Geringer et al., 2015; Miksza \& Tan, 2015). Research findings have also indicated possible factors influencing practice efficiency such as self-regulation skills (Prichard, 2017), motivation orientations (Schmidt, 2005; Zelenak, 2014), and social influences (Hickok, 2009; Liu, 2009; Petersen, 2018). Although researchers have examined middle and high school band students' practice strategies (Austin \& Berg, 2006; Christensen, 2010; Hamlin, 2014; Miksza, 2007) and motivation orientations (Hallam, 2002; McCormick \& McPherson, 2003; Schmidt, 2005), there have been few studies that involved collegiate musicians (Byo \& Cassidy, 2008; McCormick \& McPherson, 2003). Further investigations could inform collegiate instrumentalists' practice habits, optimize their technical skills, and allow instructors to know their students' challenges so they can provide lessons with students' needs in mind. In this review of literature, I will summarize the practice strategies, motivation orientations, and social factors affecting instrumental practice for musicians ranging from beginners to professionals. 


\section{Deliberate Practice}

Deliberate practice refers to engagement in structured activities designed to improve performance in a domain (Ericsson et al., 1993). Specifically, it involves creating a learning process that includes "a well-defined task with an appropriate difficulty level for the particular individual, informative feedback, and opportunities for repetition and corrections of errors" (Ericsson, 1996, p. 21). Because the purpose of practice is to improve performance - which includes time and effort - the perception of enjoyment may not be maintained in the long-term while engaging in an activity (Ericsson et al., 1993). Deliberate practice has been regarded as a necessary way to attain expertise in games, sports, education, and music. Research findings have indicated that deliberate practice is beneficial to overcome weaknesses and carefully monitor the progress of learning (Bonneville-Roussy \& Bouffard, 2015; Campitelli \& Gobet, 2011; Ericsson et al., 1993; Horrocks et al., 2016).

Ten years of deliberate practice in a domain has been suggested by researchers as necessary to achieve expertise (Chase \& Simon, 1973; Ericsson, 1996; Krogius, 1976; Patel et al., 1996). For instance, Chase and Simon (1973) indicated that chess players have to accumulate around 10 years of experience to attain an international level of skill. Consistent with their findings, Krogius (1976) noted that chess players who went from first learning the rules of chess to reaching international class took approximately 11.7 years if they were introduced to chess after the age of eleven. Similarly, in the medical field, it took, on average, 10 years to develop from a beginner first entering medical school to a highly trained specialist (Patel et al., 1996). However, Macnamara et al. (2014) found that deliberate practice could explain $26 \%$ of the variance in performance 
for games, $21 \%$ for music, $18 \%$ for sports, $4 \%$ for education, and less than $1 \%$ for professions, so it may be not as important as previously described when attaining expertise and skills. Given these findings, it is necessary to take into account individual differences and other factors such as motivation when considering the differing explanations of deliberate practice. Although these issues have been debated extensively, accumulated years of deliberate practice have been widely acknowledged as being connected with achieving expertise (Campitelli \& Gobet, 2011).

\section{Deliberate Practice in Instrumental Learning}

The amount of time spent in deliberate practice has been considered as an indicator when distinguishing among the skill level of musicians. Ericsson et al. (1993) conducted two research studies related to musicians. In the first study, they divided violinists into three groups of differing skill levels labeled as the best violinists who had the potential to attain international level as soloists, good violinists who were chosen by professors from the school of music, or students who were from the music education department and specialized in the violin (i.e., planned to become music teachers after graduating). All participants agreed that practice alone was the most effective way to improve violin performance. Through retrospective estimates of weekly practice, the best violinists practiced approximately 19.2 hours per week, followed by the good violinists (16.8 hr/week) and music teachers $(9.1 \mathrm{hr} /$ week $)$. In a similar study, participants included expert pianists and amateur classical pianists, and the researchers found that "the expert pianists started on the average four years earlier than the amateurs; their average amount of practice increased each year until it attained its current high level, whereas the amateurs maintained their early levels until adulthood" (p. 386). In these studies, 
musicians' expertise development was predicted by the amount of time spent in deliberate practice.

A positive relationship between the amount of time spent in deliberate practice and performance achievement has been found across different age groups. Sloboda et al. (1996) indicated that pre-college musicians' musical achievement positively correlated with the amount of formal task-oriented practice. Consonant with previous findings, Bonneville-Roussy and Bouffard (2015) confirmed the positive relationship between the frequency of deliberate practice and achieving an elite level of musical performance for collegiate musicians. Given this evidence, musicians should spend time in deliberate practice to aid in the development of their expertise.

Deliberate practice strategies include structured practice sessions with goals, seeking feedback actively, and correcting errors immediately. For example, Barry (1992) assigned 55 brass and woodwind students between 7 th and 10th grades to either a free practice group or a structured practice group and asked them to complete four short practice sessions distributed across two weeks. Findings from the post-test showed that students from the structured practice group gained higher scores than those who practiced without guidance. Likewise, Miksza (2007) asked high school band students to practice with designated practice strategies, to rate their practice efficiency, and to complete a practice survey. Analysis of audio recordings of participants' practice sessions and selfreport questionnaires indicated that practice strategies that included repeating sections, whole-part-whole practice, and slow practice were helpful for improving performance. However, musicians who tended to practice without goals and plans reported using few 
effective practice strategies with limited awareness of correcting errors and self-reflection (Hallam, 1997; McPherson \& Renwick, 2001; Prichard, 2017).

Music practice research findings have revealed a positive relationship between the application of deliberate practice and music expertise. However, despite the important role of deliberate practice, the effect of specific practice strategies, motivation orientations, and social factors should also be taken into account when considering expertise development.

\section{Instrumental Learning and Practice}

\section{Practice Strategies}

Musicians' practice strategies are learned from the guidance of instrumental or vocal teachers. Teachers "show them (students) how to practice, to set manageable and appropriate goals for their progression, and to monitor the success or otherwise of the practice strategies they employ while learning the instrument" (McPherson \& Davidson, 2002, p. 154). Especially for younger students, these instructions need to be codified in a set of procedures for directing their home practice (Barry \& Hallam, 2002). Prichard (2017) found that after receiving four weeks of practice instruction, middle school ensemble students could list various practice strategies and apply practice objectives that were not evident from a pre-intervention test. Petersen (2018) explored the ways in which four high school orchestra students learned to practice their instruments. All students reported that they principally "learned how to practice from their orchestra teachers" ( $p$. 119). Consequently, teachers' instructions are critical in enhancing students' abilities to identify helpful technical skills that they could use for improving practice quality. 
As performance experiences accumulate, musicians increasingly apply more effective practice strategies to improve their performance ability (Hallam, 1997; Hallam et al., 2012). Compared with beginners, professionals can list more practice strategies and explain how and when to use them. More specifically, advanced musicians were found to be flexible in revising, adapting, and changing individual action plans when performing challenging pieces (Concina, 2019; Downing et al., 2009; Lehmann, 1997). McPherson and Renwick (2001) conducted a longitudinal study about practice strategies implemented by seven instrumental beginners between seven and nine years old. Through observation of videotapes, they found that most practice time was spent playing through pieces, but errors were either ignored or corrected by repeating notes. Additionally, Hallam et al. (2012) examined beginning through pre-college level students' practice strategies and identified positive relationships between grade level and adoption of practice strategies, using a metronome and listening to recordings, and correction of errors. Meanwhile, a negative relationship was identified between grade level and applying ineffective strategies. Given these findings, the ability to flexibly apply effective practice strategies has been closely associated with the accumulation of professional knowledge.

Researchers have found mixed results regarding applying practice plans and routines. Barry (1992) investigated brass and woodwind players between grades 7 and 10 and found that a structured practice routine was an effective means of improving musical performance. Despite the importance of organizing practice, collegiate musicians were found that they were less frequently to plan their practice sessions and manage strategies such as "setting aside blocks of time to practice, ensuring effective use of the practice 
time, organizing the study environment, and committing oneself to complete practice goals" (Nielsen, 2004, p. 426). However, Byo and Cassidy (2008) found music education majors generally used a static practice routine. Therefore, they proposed that this habit may lead to a potential problem: when students had limited practice time, they were more likely to leave practice goals found at the bottom of the list undone. The findings of these studies indicate that collegiate musicians should learn how to flexibly organize practice and make individual plans that can adjust as tasks and practice time change.

Adopting different approaches to conduct repetitive practice may produce disparate performance achievement outcomes. For example, skills such as going back to the beginning and starting again when making a mistake have been identified as ineffective practice strategies (Hallam et al., 2012). In contrast, repeating sections in combination with varying tempos was suggested by researchers as a helpful approach (Miksza, 2007; Miksza et al., 2012; Miksza \& Tan, 2015). For instance, collegiate musicians who frequently used repeat section (i.e., repeating a passage longer than one measure) along with slow practice exhibited higher performance achievement than those students who did not repeat small sections (Miksza \& Tan, 2015). Likewise, expert musicians tended to repeat small sections interspersed with longer passages (Chaffin \& Imreh, 2001) and varying tempos to evaluate progress (Graaff, 2014). As expertise develops, musicians are more likely to adopt repetitions along with identifying explicit goals to be achieved rather than mechanically playing through excerpts repeatedly (Gruson, 1988; Hallam et al., 2012).

Applying analytic strategies (i.e., analyzing the structure of a piece and identifying difficult sections) has been recommended for improving musicians' practice 
efficiency. Hamlin (2014) developed a theoretical model of deliberate practice and found that "the ability to listen critically and evaluate performance, being able to hear the sound of the music in one's head, and the ability to monitor one's thoughts and behaviors to regulate practice are critical to effective practice" (p. 100) for high school band students. Rohwer and Polk (2006) labeled 8th-grade students' practice habits in four ways: (1) holistic, noncorrective practicers who played through the piece from beginning to end without stopping for errors; (2) holistic, corrective practicers who ran through the piece and only stopped for errors; (3) analytic, reactive practicers who stopped to fix problem sections; and (4) analytic, proactive practices who practiced the areas they thought would be a challenge to them. Findings indicated that practicers who used analytic approaches were rated significantly higher in performance than holistic practicers.

Mental practice, which refers to the use of imagery as opposed to the practice of physical skills in practice sessions, is a necessary technique for musicians to achieve expertise because it is beneficial for improving the effectiveness of practice, for overcoming technical challenges, and for enhancing memory (Gabrielsson, 1999). Specifically, Connolly and Williamon (2004) found that mental practice helped in the initial stages of learning when an overview of the work was being constructed and in the final stages of preparing the work for performance. Cahn (2008) examined the efficacy of college students' different practice methods (e.g., physical practice and mental practice, with combinations of $33 \%$ physical practice and $66 \%$ mental practice, or $66 \%$ physical practice and $33 \%$ mental practice) on the task of performing a tonal pattern over two separate chord progressions. He found that participants performed better on an improvisation task while using mental practice alone and when combining 33\% physical 
practice and $66 \%$ mental practice. However, while engaging in a difficult task, using physical practice alone and 66\% physical practice and 33\% mental practice were more effective in practice. In comparison with physical practice, mental practice may be seldom used by collegiate musicians (Cahn, 2008; Lim \& Lippman, 1991) but remains a necessary skill to achieve expertise, develop the ability to play from memory and by ear, and improvise (McPherson, 2005). Teachers and their students should consider actively applying mental practice strategies in their daily routines.

Using practice tools such as a metronome and listening to recordings has been recommended in practice. Rosenthal et al. (1988) found that listening to models of teachers' and advanced musicians' performances can contribute to practice, and that "listening to a model alone (without an opportunity to practice) seems to be about as effective as practice with the instrument in hand" (p. 254). Although using a metronome can facilitate performance achievement, only a small number of school band students followed the suggestion from their teachers to use one during practice (Miksza, 2007; Miksza \& Tan, 2015). Conversely, Hallam et al. (2012) indicated that musicians at higher levels of expertise reported using a metronome as well as recording and listening to their practice recordings more often than those with lower levels of expertise. These findings were consonant with the results of a study by Geringer et al. (2015), who found that advanced string musicians reported using a metronome and listening to model recordings with greater frequency than players from lower-level ensembles. Given these findings, instrumental teachers should emphasize the benefits of applying practice tools while practicing, especially for beginners, to help optimize practice habits. 
Musicians may lack the awareness necessary for correcting errors while practicing. For example, Hallam (1997) found that almost $60 \%$ of beginning and advanced musicians left errors uncorrected when learning a new piece. Likewise, Pitts and Davidson (2000) indicated that young instrumentalists were only conscious of difficulties when they struggled or stopped, rarely identifying errors such as inaccurate rhythm or pitch, which probably because of incapability to identify errors while practicing. However, without the correction of mistakes in practice, students would actually perform with an increasing number of errors (Barry, 1992). Fortunately, students with higher levels of expertise were more likely to realize the importance of error correction than lower levels did and to avoid repeating errors while practicing (Hallam et al., 2012).

Additional practice strategies closely related to higher performance achievement include marking the music, varying the tempo, slow practice, and keeping a practice diary. Donald (1997) compared two practice procedures with different tempi performed by 40 advanced and intermediate level pianists. Results indicated that alternation of slow and fast tempos was slightly more effective than incremental tempo adjustment. Miksza (2007) found that approximately $80 \%$ of high school band students used marking the music and adopted slow practice as strategies to improve performance. Professional musicians also frequently mentioned using slow practice and gradually speeding up as a way to learn challenging musical excerpts (Harnum, 2013).

Musicians should master and apply various practice strategies to achieve expertise. In the musical learning journey, instrumental teachers play an important role in developing their students' technical skills and analytical thinking. Considering that 
musicians spend much time in individual practice to achieve performance goals, in addition to the application of effective practice strategies, other factors such as selfregulation skills and attitudes and beliefs toward practice also impact musicians' expertise development.

\section{Self-Regulation}

Self-regulation is a framework that involves learners' efforts in metacognitively, motivationally, and behaviorally guiding their own learning process (Zimmerman, 1986). It is an open-ended cyclical process that occurs in three phases: forethought, performance/volitional control, and self-reflection. Forethought refers to the thought processes that come before engaging in a task such as goal setting, self-efficacy, and outcome expectations. Performance/volitional control represents activities happening while executing a task involving self-instruction, attention focusing, and metacognitive monitoring. Self-reflection, taking place after the learning process, affects learners' subsequent response to the experience including self-evaluation and self-reaction (McPherson \& Zimmerman, 2011).

Self-regulation has been studied extensively in music practice literature. McPherson and Zimmerman (2002) summarized several dimensions applicable to music practice by reviewing extant studies including method (application of systematic strategies), practice time (managing and organizing the use of time), and behavior (application of metacognition and self-evaluation). Leon-Guerrero (2004) examined the self-regulation strategies used by middle school instrumental musicians. There were 25 specific self-regulation strategies divided into four categories: repetition, musical elements, non-specific tasks, and non-playing. Most of the strategies were applied in 
practice by participants, especially repetition, which accounted for approximately $87 \%$ of the instances. Horsley (2019) interviewed six instrumental instructors and reported that they suggested their students adopt self-regulation skills during practice including selfevaluation, goal setting and planning, and seeking assistance.

Self-regulation skills are related to instrumental practice, particularly in practice behaviors, decision making, and time spent in practice. For example, Miksza and Tan (2015) found that collegiate musicians who perceived themselves to be self-regulated and efficient in their practice were more likely to display determination to accomplish their practice goals, demonstrate metacognition and self-awareness, and experience flow than those musicians who did not. Nielsen (2001) indicated that advanced conservatoire students demonstrated extensive self-regulation skills to optimize their learning and musical performance such as setting specific goals, using self-instruction, and monitoring themselves selectively at a detailed level. With regard to intermediate level musicians, self-regulated students reported the application of effective practice strategies such as varying tempo and repeating excerpts longer than four measures in length while practicing (Miksza et al., 2012). Musicians with high self-regulation skills tended to manage and plan their practice such as choosing, modifying, and adapting practice strategies based on their actual needs.

Mixed results regarding self-regulation and expertise development have also been reported. For example, Prichard (2017) identified positive relationships between selfregulation scores and the total number of listed practice strategies and time spent in practice among middle school band students. However, Austin and Berg (2006) found that there was no relationship between sixth-grade instrumentalists' performance 
experience and practice regulation. Other researchers reported that self-regulation ability might be influenced by learning and social contexts such as family (Upitis et al., 2017). In building an integrative framework, Bonneville-Roussy and Bouffard (2015) proposed that integration of self-regulation and deliberate practice can provide a developed understanding of the association among practice strategies, practice time, and performance achievement.

\section{Practice Attitudes and Beliefs}

Researchers have found discrepancies among descriptions and expectations with regard to music practice between teachers and their students (Kostka, 2002; Miksza \& Tan, 2015). For example, Kostka (2002) examined 127 collegiate studio music teachers and their 134 students and found that although the majority of teachers encouraged their students to use a specific practice routine, $55 \%$ of the students admitted that they did not do so. Furthermore, almost all of the teachers substantiated that they discussed practice strategies with their students, whereas $67 \%$ of the students reported that practice strategies were not discussed in lessons. Even though students can list various practice strategies, they may overlook them while practicing (Byo \& Cassidy, 2008; Christensen, 2010). Barry (2007) indicated that collegiate musicians applied very limited techniques during practice and mainly used repetition or other skills emphasized by instructors such as verbalizations and examples from a lesson. Consistent with previous findings, Miksza and Tan (2015) found that practice strategies taught by studio teachers were not reflected in their students' responses to open-ended questions. Discrepancies concerning what is expected and what may actually be taking place during practice should be investigated further. 
Musicians' attitudes and beliefs about music practice are different from reported stereotypes across expertise levels. It is generally assumed that advanced musicians learn practice strategies from their teachers. However, through interviews with eight expert musicians, Harnum (2013) found seven of them stated that their studio teachers mainly provided encouragement and inspiration, whereas "figuring out the most effective way to practice was a task left for the musicians to discover on his or her own" (p. 350). Hallam et al. (2012) found that the time spent in practice did not reflect the extent of how much beginning through advanced musicians enjoyed practicing. Austin and Berg (2006) investigated 6th-grade musicians' practice and indicated that students with more years of instrumental learning reported being less motivated to practice than their peers who had less learning experience. In other words, daily practice was deemed as a more laborious task to those who had more years of instrumental learning rather than a time of experiencing and appreciating music.

\section{Practice Motivation}

Motivation is an important factor for instrumentalists to achieve practice goals and persist in learning. It has been found to explain approximately $20 \%$ of the variance in musical achievement and related behaviors such as time spent in practice, effort, and enjoyment (Asmus, 1994). Specifically, intrinsic and extrinsic motivation (Hallam, 2002; Schmidt, 2005), self-efficacy (McCormick \& McPherson, 2003; McPherson \& McCormick, 2006; Zelenak, 2014), and achievement goal theory (Miksza, 2009, 2010; Nielsen, 2008; Schmidt, 2005) have been found closely related to performance outcomes and practice time so that has attracted attention from researchers, teachers, and students. 


\section{Intrinsic and Extrinsic Motivation}

Intrinsic motivation refers to behavior that is driven by internal factors such as interest and enjoyment (Ryan \& Deci, 2000). In contrast, extrinsic motivation is defined as behavior driven by external rewards such as praise and grades (Ryan \& Deci, 2000), or in the case of music practice, for acquiring approval from teachers or audience members. Therefore, instrumental instructors are expected to arouse students' intrinsic motivation and to instill the inherent worth of practice, because it would facilitate musicians' passion and commitment to instrumental learning.

Intrinsic motivation can positively influence students' musical performance. McPherson and McCormick (2000) noted that intrinsic motivation was related to practice time and measures of performance achievement for band students from elementary to high school age. Similarly, Miksza (2006a) found that middle school band students' intrinsic motivation, including meeting personal goals, solving problems, and making improvements positively, correlated with their practice efficiency and time spent in practice. Moreover, Bangs (1992) indicated that intrinsic motivation was correlated with musicians' creativity. To cultivate intrinsic motivation, instrumental teachers should avoid differentiating students with grades and ability (Sandene, 1997; Schmidt, 2005) and provide positive feedback to encourage musicians to practice (Hruska, 2011; Sandene, 1997).

\section{Achievement Goal Theory}

Achievement goal theory refers to a psychological theory of intrinsic motivation focusing on how beliefs and cognition direct individuals toward achievement or success, especially in relation to two goal orientations: mastery and performance (Dweck, 1986; 
Kremer et al., 2012; Nicholls, 1989). Generally, mastery goals are thought to improve personal competence by the acquisition of new knowledge or skills, whereas performance goals, also known as ego or ability goals, are developed to present oneself as competent in someone else's eyes (Nicholls, 1989).

Mastery goal orientation and performance goal orientation can bring different learning outcomes. Schmidt (2005) found that secondary school musicians' success was closely related to mastery and cooperative orientations with less emphasis on competitive and performance orientations. High school musicians who had mastery goal orientations were more intrinsically motivated and self-regulated in instrumental learning than those who had performance goal orientations (Bailey, 2006). However, Nielsen (2008) indicated that first-year collegiate musicians' achievement goals might not influence performance achievement. Despite mixed research findings, it appears that mastery goal orientation can facilitate musicians' engagement in more complex activities and help them attain greater achievement in comparison with performance goals (Bailey, 2006; Sandene, 1997; Schmidt, 2005)

Achievement goal theory has been subdivided into four categories (Elliot, 2005; Elliot \& McGregor, 2001). Mastery-approach goals focus on achieving task-based or intrapersonal competence such as skill development, mastery of task, and selfimprovement. Mastery-avoidance goals refer to avoiding task-based or intrapersonal incompetence, because the individual believes they will not be good at it. Performanceapproach goals have been defined as achieving normative competence with the aim to perform better than others. Performance-avoidance goals focus on avoiding normative incompetence with aims to avoid performing badly compared to others. Taken together, 
mastery-approach goals and performance-approach goals contribute to making progress in music learning. In contrast, mastery-avoidance and performance-avoidance goals may bring negative learning experiences and outcomes (Elliot \& McGregor, 2001; Schmidt, 2005).

Achievement goal theory is related to musical creativity, emotional influence, and performance achievement (Tan \& Miksza, 2019; Wang et al., 2018). For example, band students who displayed mastery-approach goals more frequently experienced flow during rehearsals that facilitated their creativity more so than those who did not display similar goals (Tan \& Miksza, 2019). Mawang et al. (2020) found that secondary school students' musical creativity was positively related to mastery-approach goals but negatively correlated with performance-approach and performance-avoidance goals. With regard to emotional influence, Lacaille et al. (2016) indicated that performance-approach and performance-avoidance goals were associated with negative emotional outcomes such as performance anxiety and intentions of dropping out. In contrast, mastery-approach goals were positively correlated with an individual's learning enjoyment (Wang et al., 2018). As a result, music teachers should build mastery-oriented learning environments and avoid emphasizing external rewards and peer competition when providing instructions to their students.

\section{Self-Efficacy}

Self-efficacy refers to individuals' beliefs concerning their ability to accomplish a task. Individuals with high self-efficacy are more likely to execute or overcome difficult tasks, whereas individuals tend to avoid tasks when their self-efficacy is low. Selfefficacy beliefs can motivate individuals to be more actively involved in a task and work 
harder and longer (Bandura, 1997). Therefore, educational researchers have proposed that teachers should help students learn how to manage their self-efficacy beliefs, which can, in turn, positively affect self-regulation, persistence, and subsequent task-based achievement (Bandura, 1997; Pajares, 2003; Zimmerman, 2000).

Self-efficacy has been found to be a critical predictor of cognitive ability and performance achievement. For example, Nielsen (2004) found a positive relationship between self-efficacy and the ability to think critically and organize instrumental practice among first-year collegiate musicians. Additionally, self-efficacy was positively related to performance quality among pre-college instrumentalists (McCormick \& McPherson, 2003). Congruent with previous research, self-efficacy was found to be the most important predictor of performance achievement (McPherson \& McCormick, 2006). Zelenak (2014) noted that music aptitude scores also could predict self-efficacy in music performance for middle and high school students who enrolled in band, orchestra, and chorus. Given these findings, teachers should establish proximal goals for and actively encourage their students during the teaching and learning process (Pajares, 2003).

\section{Social Influences}

\section{Parental Involvement}

Parental involvement is a key element to facilitate performance outcomes in the early stages of instrumental learning. As with general education homework, children may not view instrumental practice as their own responsibility but instead rely on parents for reminders and help. Accordingly, parents need to be aware of children's learning ability and have methods to reasonably guide practice. Creech (2010) suggested that children's practice could be improved when parents: (a) elicit their children's views regarding 
appropriate parental involvement, (b) negotiate with their children over practice issues within guidelines set by the teacher, (c) provide a structured home environment for practice, (d) help to build a good teacher-pupil rapport, (e) communicate with the teacher in relation to the child's progress, and (f) remain as an interested audience. Over the course of instrumental practice, parents seem to play a role as a scaffold. They assist in forming practice habits, cultivating self-regulation skills, and gradually stepping back from supervision (Sloboda \& Davidson, 1996; Upitis et al., 2017).

Positive relationships between parental involvement and performance achievement have been found (Davidson et al., 1995; Driscoll, 2009; O’Neill, 1997). Children whose practice was supported and assisted by their parents were more likely to achieve musically (Hickok, 2009; McPherson \& Davidson, 2002). Specifically, Zdzinski (1996) found that the parental involvement of secondary school instrumentalists promoted affective outcomes (i.e., practice motivation), cognition of musical elements (i.e., rhythm, tone, and chord), and performance achievement as measured by the Watkins-Farnum Performance scale. After the initial burst of excitement has worn off, beginners may present a mix of emotions toward instrumental practice, many of which may seem unpleasant. Therefore, parents need to help their children cope with emotional difficulties. Although parental involvement is important in children's musical achievement, Ho (2011) argued that children could develop an independent interest in music based on their own needs and aspirations. Forcing children to practice may result in unrealistic expectations that can cause deleterious influences on future development and learning motivation. As a result, adopting appropriate ways for parents to support 
instrumental practice and establishing a productive practice environment for beginners could help students refine their regulatory behaviors.

\section{Siblings Support}

Siblings may affect each other's instrumental learning. Liu and Sims (2008) focused on the influence of sibling relationships on music learning and how siblings interacted with each other when studying music. Results showed that siblings benefited from their interactions, and competition between them played an important role in motivating and encouraging the music learning process. Further, Liu (2009) examined interactions between siblings in music learning with participants who were from five, two-child families. Findings indicated that older siblings provided instruction in addition to being role models for the younger sibling, and younger siblings were inclined to request information from their older siblings. All siblings held a positive attitude toward one another in the aspect of rivalry in music learning. Consonant with prior research, Fung (2018) found that older siblings served the role of kin-tutors or co-parents when providing instruction to their younger siblings, supporting the development of their musical ability.

\section{Peer-Assisted Learning}

Peer-assisted learning can bring positive learning outcomes to both the tutor and the tutee. Webb (2015) video recorded three high school students instructing sixth-grade students in a local orchestra. In this program, these tutors experienced increased motivation for learning and a strong sense of confidence and ownership. Similarly, Johnson (2015) recommended that peer-assisted learning was helpful because it allows students to organize their own learning experience, to explore unknown or less developed 
concepts, and to cultivate a sense of responsibility for learning with peers together. Petersen (2018) indicated that peer tutoring is an effective way of improving one's own ability because explaining and teaching are procedures to use when consolidating existing knowledge.

\section{Conclusion}

Identifying and applying successful practice strategies appear to be required for attaining instrumental performance expertise. With years of learning, accumulated experiences contribute to a wealth of applicable practice strategies for musicians but using them effectively still requires careful consideration. Different from general assumptions that instrumental learning mainly involves interactions between teachers and students, many contextual factors, such as family influence and peer learning, and psychological factors, including intrinsic and extrinsic motivation, self-efficacy, and achievement goal theory, can also influence practice time, interests, and achievement.

Although researchers have examined practice strategies used by musicians (Austin \& Berg, 2006; Concina, 2019; Cremaschi, 2012; Hallam, 2001a; Hallam et al., 2012; Miksza, 2007; Schmidt, 2005; Sloboda et al., 1996), few studies have involved collegiate instrumentalists and their practice motivation orientations (Cremaschi, 2012; Kostka, 2002; Nielsen, 2008). Additional research of collegiate instrumentalists' practice habits and behaviors could include: (a) what practice strategies they apply in practice sessions, (b) what factors may motivate and/or hinder their practice, and (c) relationships between practice time and motivation orientations. Due to different perspectives in relation to practice routine - in which some researchers encouraged collegiate musicians to have structured practice sessions (Kostka, 2002; Nielsen, 2004), but others suggested 
flexibly adjusting practice plans based on personal needs (Byo \& Cassidy, 2008)—future studies could provide insight into how advanced musicians organize their practice routine and possible factors that may affect the organization of their practice routine. Therefore, investigating collegiate musicians' practice habits and motivation orientations may provide valuable information regarding instrumental learning for instructors to optimizing their teaching.

Focusing on collegiate instrumentalists may be helpful in understanding how they practice and the potential factors that influence practice. If practice strategies used by collegiate musicians differ from instrumental teachers' assumptions, researchers could report ways in which instructors could better meet the needs of their students. Moreover, given their knowledge of students' practice habits and motivation orientations, instructors would know what aspects need to be emphasized and taught as a result of providing effective feedback and proximal goals to their students. Exploring factors that potentially affect musicians' practice will assist in building a supportive practice environment that may help contribute to expertise development. These efforts would hopefully sustain musicians' motivation to practice and help them develop a passion for music in the long term. 


\section{Chapter Three}

\section{Practice Habits and Motivation: A Qualitative Descriptive Study of Graduate Instrumentalists}

To succeed professionally, musicians must learn various practice strategies and remain motivated when practicing their instrument. Although time spent in practice may distinguish the expertise level of musicians (Ericsson et al., 1993; Jørgensen, 2002), the adoption of effective practice strategies such as repetition (Graaff, 2014; Miksza, 2006a), analytic strategies (Duke et al., 2009), using a metronome and listening to model recordings (Geringer et al., 2015), self-regulation skills (Araújo, 2016; Nielsen, 2001), and organizing practice routines (Byo \& Cassidy, 2008) are essential for performance achievement. Additionally, motivation orientations play an important role in the persistence of instrumental learning. Musicians who exhibited intrinsic motivation reported more enjoyment and interest in instrumental learning than those musicians who demonstrated extrinsic motivation (Diaz, 2010; Moder, 2013; Yoo, 2020). It is evident that advanced musicians' expertise development involves the use of effective practice strategies, an organized practice routine, and personal motivation.

Although repetition has been reported as the most common practice strategy used by musicians (Austin \& Berg, 2006; Byo \& Cassidy, 2008), merely playing through music from beginning to end without stopping while practicing has been identified as an ineffective practice strategy (Hallam et al., 2012). For example, middle school band students were inclined to adopt playing through music exercises repeatedly as a primary strategy (Prichard, 2017, 2020; Rohwer \& Polk, 2006). However, collegiate musicians applied repetition in small sections and through whole-part-whole practice (Miksza, 
2006b). Professional musicians repeated small sections interspersed with longer passages (Chaffin \& Imreh, 2001; Miklaszewski, 1989), and alternated between slow and fast tempos to evaluate progress and achieve goals (Graaff, 2014). Given accumulated instrumental practice experiences, musicians seem aware of the necessity of combining repetition with other practice skills for improving practice efficiency.

The frequency of applying analytic practice strategies (e.g., pinpointing errors, identifying difficult sections) has been associated with musicians' performance achievement and musicianship. For example, Rohwer and Polk (2006) invited four band directors to use a criteria-specific rating scale to evaluate eighth-grade instrumentalists' performance achievement according to their practice recordings. Results indicated that holistic practicers - those who played through the exercise repeatedly-received lower scores than analytic practicers who often stopped at difficult sections and used remedial techniques such as intentionally repeating troublesome measures and practicing with varied tempo to improve performance. Although pre-college musicians were less likely to apply analytic practice strategies while practicing (Hallam et al., 2012), advanced musicians tended to isolate challenging sections and analyze repertoire while learning (Nielsen, 1999). Similarly, Duke et al. (2009) observed and ranked collegiate pianists' accuracy of practicing a difficult passage at a prescribed tempo. They found that topranked pianists were more likely to pinpoint and isolate errors and systematically vary tempos to achieve goals in the practice session than the lower-ranked participants. In sum, instrumental teachers should provide instruction regarding the application of analytic strategies because they can help musicians listen critically, monitor thoughts and behaviors, and facilitate practice efficiency (Hamlin, 2014). 
Applying practice tools such as a metronome and tuner have been recommended for students' instrumental practice. However, although teachers suggested listening to model recordings and using a metronome while practicing, only a small number of students applied these practice tools (Austin \& Berg, 2006; Perez, 2011). Geringer et al. (2015) found that middle and high school string musicians in advanced ensembles reported using a metronome and listening to recordings more often than players from lower-level ensembles. However, engraining these behaviors in students' practice may require teachers' help. Compared with students who have no instruction from instrumental teachers, middle school musicians were more likely to use a metronome and tuner after receiving three weeks of systematic instruction from teachers (Prichard, 2020). Considering that using practice tools may facilitate practice progress, music teachers and students should consider their use in daily practice.

Musicians often apply self-regulation skills in practice sessions (Araújo, 2016; Bonneville-Roussy \& Bouffard, 2015; Nielsen, 2001). Common self-regulated behaviors include goal setting, metacognitive thinking (i.e., structure, monitor and revise practice plans toward specific performance goals), planning and time management, selfevaluation, actively searching resources, and help-seeking (Austin \& Berg, 2006; Hallam, 2001b; Miksza, 2006a). However, these behaviors were seldom used by beginning musicians in practice (McPherson \& Renwick, 2001). In contrast, advanced musicians demonstrated various self-regulation skills. For example, Nielsen (2001) observed practice sessions of two accomplished organists with a high level of technical skill. Findings indicated that they adopted extensive self-regulation skills such as setting specific goals, engaging in strategic planning, using self-instruction, and monitoring and 
evaluating self-progress during practice. Further, Araújo (2016) identified three selfregulated behaviors used by collegiate musicians: (a) practice organization, (b) personal resources, and (c) external resources. Results showed that collegiate musicians mainly relied on understanding their individual strengths and weaknesses and the nature and demands of musical activities. As expertise develops, musicians gradually master extensive self-regulation skills and apply these skills based on individual needs.

Motivation orientations influence musicians' performance achievement and the persistence of instrumental learning. Compared with intrinsic motivation driven by determinants such as interests and enjoyment, extrinsic motivation is driven by external rewards including grades and praise (Ryan \& Deci, 2000). Researchers found that passion and enjoyment were the main reasons why students continued music participation (Moder, 2013; Yoo, 2020). Additionally, Schmidt (2005) identified that middle and high school musicians' performance achievement was positively correlated with their intrinsic motivation. Collegiate musicians' responses indicated that they were more inclined to exhibit intrinsic motivation than extrinsic motivation in ensemble learning contexts (Diaz, 2010). However, professional musicians exhibited extrinsic, intrinsic, and mixed motivation orientations toward instrumental practice (Hallam, 1995). Given these findings, instrumental teachers should provide positive feedback (Hruska, 2011; Sandene, 1997) and promote students' perceptions of competence (i.e., the need to produce desired outcomes and to experience mastery) and relatedness (i.e., the need to feel connected to others) to enhance students' intrinsic motivation in instrumental learning contexts (Yoo, 2020). 
Although previous research focused on musicians' practice habits including time spent in practice (Ericsson et al., 1993; Jørgensen, 2002) and the application of technical skills (Araújo, 2016; Austin \& Berg, 2006; Barry, 1992; Hallam et al., 2012), there have been few investigations relating to the organization of collegiate musicians' practice routines (Byo \& Cassidy, 2008) and motivation orientations (Diaz, 2010). Given that these variables are associated with expertise development, it seems important to explore graduate instrumentalists who may be in a unique situation: they enroll in challenging courses, have a teaching assistantship or other job with little free time to practice their instruments, and feel pressure to prepare for the future. Because most of them may pursue instrumental performance and education as their career, their practice habits may influence their future students. Findings from the current study will help studio instructors learn graduate instrumentalists' practice habits, specific reasons that motivated and hindered their practice, and assist in developing their students' problem-solving skills and motivation to practice. Moreover, other musicians could learn from the successful organization of graduate instrumentalists' practice routine and the effective strategies used in their practice sessions.

The purpose of this study was to examine graduate instrumentalists' practice habits and motivation orientations. The research questions included: (1) How do graduate instrumentalists organize their practice routine? (2) What common practice strategies do graduate instrumentalists who are from different instrumental groups apply during practice? (3) What factors may motivate or hinder graduate instrumentalists' practice? 


\section{Method}

\section{Research Design}

I used a qualitative descriptive design to investigate graduate instrumentalists' practice habits and motivation orientations. This methodology requires that researchers "draw from a naturalistic perspective and examine a phenomenon in its natural state" (Kim et al., 2017, p. 2), stay close to the data, and provide interpretations with lowinference (Sandelowski, 2000). Such investigations can provide "comprehensive descriptive summaries and accurate details of the data collected and present (findings) in a way that makes sense to the reader" (Kim et al., 2017, p. 2). In this qualitative descriptive study, I examined four graduate instrumentalists' practice routines, the strategies they applied while practicing, and their practice motivation. Data included questionnaires, participants' video-stimulated recall, and semi-structured interviews, and my own researcher journal and memos.

Two music education faculty members with previous qualitative research experience at the institution where the data was collected reviewed the design prior to data collection. They provided suggestions with regard to the sequence of the interview questions, the interview protocol (i.e., perceptions while watching the practice video), and the need to conduct pilot interviews with instrumentalists from different instrumental families. I made revisions based on their suggestions, including adding a time requirement for the practice video and additional interview questions, before sending recruitment emails to potential participants.

Pilot interviews were conducted with three musicians (a pianist, violinist, and trumpeter) who were pursuing a graduate degree in music education. Each participant had 
more than 15 years of experience on their primary instruments. They provided a videotaped practice recording, filled out the questionnaire, described the practice strategies they used and the purpose of using them along with the playback of the practice recording, and agreed to be interviewed.

Pilot participants were initially asked to provide a practice video of around an hour that may or may not include break(s). However, after interviewing the pianist and the violinist, they both mentioned that they felt exhausted after practicing around an hour, even though the break was allowed, and the practice video might not represent a typical daily practice session. Their feedback prompted me to alter the time requirement of the practice video for the trumpet player. I then asked for a video recording that represented a typical practice session and suggested including etude(s) or solo piece(s). The trumpet player's practice recording and semi-structured interview offered sufficient information regarding practice habits and motivation. Therefore, I decided not to specify participants' practice time in the current study. Unlike the trumpet and violin pilot participants, memorization dominated the practice session of the piano player. As a result, I decided to recruit participants who were pursuing a master's degree in music performance whose emphases included brass, percussion, strings, and woodwinds.

\section{Participants}

Considering that similar findings were identified after analyzing pilot interviews with three graduate musicians, I used purposeful sampling (Patton, 2002) to recruit four graduate instrumentalists to participate in this study. Additionally, maximum variation sampling (Sandelowski, 2000) was used to recruit participants from different instrument families (i.e., brass, percussion, string, woodwind) in order to explore the common and 
unique practice habits due to instruments that they played. After analyzing participants' interviews and video-stimulated narrations, I was confident that four was a sufficient number of participants because I reached saturation, which implies that no new findings emerged when analyzing the fourth participant's materials. Moreover, due to rising Covid-19 cases in Fall 2020, university leaders unexpectedly decided to shift to remote learning after Thanksgiving break, which also negatively influenced data collection and research progress. Therefore, a total of four graduate instrumentalists participated in this study.

Participants were master's students in music performance from the School of Music that I attended in the Midwest region of the United States. They reported that their practice strategies were learned from various sources such as instrumental instructors, peers, self-exploration (e.g., books, research articles, workshops), and social media platforms (e.g., Facebook, YouTube). Characteristics of the four participants in this study are provided in Table 1.

\section{Table 1}

Descriptions of Participants

\begin{tabular}{ccccc}
\hline Name & Instrument & Age & $\begin{array}{c}\text { Years of } \\
\text { Learning }\end{array}$ & $\begin{array}{c}\text { Weekly } \\
\text { Practice Hours }\end{array}$ \\
\hline Dan & Tuba & 22 & 8 & 16 \\
Jack & Cello & 22 & 13 & 10 \\
Mary & Percussion & 23 & 9 & 12 \\
Sarah & Oboe & 23 & 12 & 6 \\
\hline
\end{tabular}

Note. Pseudonyms were used to protect participants' identities. 


\section{Data Collection and Procedure}

Data collection took place over three weeks in Fall 2020. Participants agreed to participate and were provided a description of the study along with an Institutional Review Board-approved consent form (see Appendix A). Data sources consisted of a videotaped practice recording, a questionnaire, video-stimulated recall, and semistructured interview with each participant. Additionally, I made notes in a researcher journal that included all interactions and discussions with the participants such as email correspondence and conversations. Similarly, researcher memos were used to track the process of data analysis and check biased descriptions throughout the research process (Charmaz, 2014). The application of researcher journal and memo writings also kept me involved in the following data analysis and allowed me to refine research findings.

\section{Phase 1: Video Recordings and Questionnaire}

After obtaining consent from participants, I asked them to provide a video recording representing their daily practice routine. The purpose of using the videos was to stimulate their recall of the practice sessions and to explain why they were choosing certain practice strategies. In order to ensure robust data, I suggested including etude(s) or solo piece(s) in the practice video. Their practice video length ranged from 19 to 56 minutes. Participants made the recordings through their smartphones or laptops, and these were sent to me via Dropbox, Box, or YouTube website links.

A questionnaire was used to collect descriptive information. I created and distributed the survey through Qualtrics software, an online survey program. In my pilot study (Liu, 2021), I adapted a 28-item practice organization and strategy scale developed by Hallam et al. (2012) to a 23-items scale under five subscales and displayed good 
internal consistency $(\alpha=.80)$. In the current study, I added one more subscale, "correction of errors" (3 items) and included two statements used by Rohwer and Polk (2006): "I can recognize errors while practicing" (adoption of systematic strategies); "I conduct silent practice" (adoption of systematic strategies); and another two statements from Pintrich et al. (1991): "I have a set practice routine" (organization); "I can stick to my practice schedule (organization)." The final scale used in this study consisted of 30 items under six subscales and displayed good internal consistency $(\alpha=.80)$. Additionally, practice motivation was measured through a scale developed from Schatt (2011) that focused on intrinsic and extrinsic beliefs of music practice. Overall, the questionnaire used in this study contained three sections: (a) application of practice strategies (30 items; see Appendix I), (b) practice motivation (9 items; see Appendix J), and (c) demographic information (11 items; see Appendix K). Participants received the electronic link to the survey and filled out the questionnaire via Qualtrics after submitting their practice video recording.

\section{Phase 2: Video-Stimulated Recall and Interviews}

Well-informed interviewees can provide important insights into specific events with rich evidence (Yin, 2009). Therefore, I used semi-structured interviews that "may remain open-ended and assume a conversational manner, but you [the researcher] are more likely to be following a certain set of questions" (Yin, 2009, p. 107). The interview process was fluid. I asked follow-up questions according to participants' responses such that a broad range of information regarding their individual practice behaviors was collected. 
Video-stimulated recall and interviews took place within 10 days after each participant had submitted their practice video and filled out the survey because they were more likely to remember their practice session. Participants were asked to introduce the piece and/or etude practiced in the recording (e.g., how long they had been learning the piece and their practice plan to provide better context for subsequent analysis). Then, each participant and I watched the practice video together, while the participant controlled the playback of the video in order to narrate practice strategies they used and the purpose for using them. I only asked questions during the video review when I identified overlooked actions. For example, if they paused playing in the recording and to think or mark the score but did not describe this process, I would ask the purpose of the action. This review process ranged from 23 to 67 minutes.

The next phase was a semi-structured interview that included questions about their perceptions and reflections toward the practice session and other aspects about practice routine and attitudes (see Appendix D). When necessary, I asked follow-up questions that encouraged participants to clarify their comments and thus helped manage the conversation by keeping it on topic (Norgaard, 2008; Rubin \& Rubin, 2011). These interviews ranged from 12 to 24 minutes.

\section{Data Analysis}

All video-stimulated recall sessions and semi-structured interviews were audio recorded. I used Otter.ai, an online speech to text transcription platform, to transcribe these audio materials. When listening to the audio recordings and checking the accuracy of transcriptions, I made edits, such as removing sounds that aid in the flow of 
conversations (e.g., hmm, ahh) and adding conjunctions to introduce dependent clauses, to enhance the clarity and readability of the transcripts.

I analyzed the data by using thematic analysis. This is a data-driven method for "identifying, analyzing, and reporting patterns (themes) within data," and the purpose is to capture important contents in relation to research questions (Braun \& Clarke, 2006, p. 79). Data collection and analysis were simultaneous. This allowed me to be reflexive and interactive when modifying and accommodating new insights with subsequent data gathering and analysis (Sandelowski, 2000). I did not use any pre-existing coding systems while analyzing participants' data. Main themes derived as findings for this study were based on the data gathered from the participants with extensive descriptions and low-inferenced interpretation (Kim et al., 2017). I used NVivo, a qualitative data analysis computer software, to record my initial codes, and grouped them into categories and themes as needed. The software enabled me to track the label used for each code, provide descriptions of concepts or themes, and note how codes, categories, and themes connect with each other in my analysis. Specific information regarding the development of codes, categories, and themes is presented in Appendix E.

\section{Trustworthiness}

Trustworthiness was achieved by external review, data triangulation, rich descriptions, member checking, and clarifying research bias (Creswell \& Poth, 2016). An external reviewer with experience conducting qualitative research reviewed $20 \%$ of data collected from each data source. Our initial overall credibility was approximately $82 \%$. We discussed each discrepancy until 100\% consensus was achieved (Denzin \& Lincoln, 2011). Moreover, I was able to triangulate robust descriptions and provide reliable results 
by collecting data from multiple sources (i.e., questionnaire, video-stimulated recall, interviews, researcher journal, memos). Memos facilitated the construction of analytic and systematic notes and allowed me to track the development of categories and themes to ensure credibility (Charmaz, 2014). Additionally, I used member checking, or "the method of returning an interview or analyzed data to a participant used to validate, verify, or assess the trustworthiness," (Birt et al., 2016, p. 1802) that allowed participants to clarify any errors in my transcription in order to improve the accuracy of the results. One of the participants offered a list of their weekly practice routine as supplementary material and answered my question about their use of slang after verifying the transcription. There were no other additions or alternations made.

I considered my positionality when approaching data analyses because positionality can influence trustworthiness and the research process, including ways to raise research questions and analyze data (Berger, 2015). My position in this study was as a musician who had the experience of learning an instrument and underwent the frustration caused by insufficient technical skills. My research bias attributes to early instrumental learning experience. For the majority time during my pre-college learning, my parents and instrumental teachers provided authoritative instructions, which resulted in my following rigid instructions. I had little chance to explore practice strategies on my own or musical styles that interested me. I found myself frustrated in instrumental practice where my musical agency was minimized by instrumental teachers and parents. Consequently, I understood participants' perceptions, dilemmas, and challenges when dealing with instrumental practice. A previous pilot study that I conducted of Chinese instrumentalists (Liu, 2021) informed my understanding of time spent in practice and the 
strategies frequently used among instrumentalists. This research experience encouraged me to explore more thoroughly the variables that can influence graduate instrumentalists' expertise development from skill acquisition to attitudes and beliefs toward music practice.

\section{Findings and Discussion}

Four themes emerged as a result of participants' responses from the questionnaire, video-stimulated recall, and interviews. Task-oriented practice routines reflected that participants tended to organize their practice sessions based on goals and practice time. They applied solution-oriented approaches to adopt multiple and effective practice strategies targeted at solving problems. Mixed motivations, including both intrinsic and extrinsic motivation, affected participants' instrumental practice. External challenges influenced learning contexts and affected psychological state negatively. All themes are supported by the analysis of categories and initial codes and revealed the practice habits and motivations of graduate instrumentalists (see Appendix E for the complete codes).

\section{Theme One: Task-Oriented Practice Routines}

Participants organized their practice routines with task-oriented principles along with flexible practice plans and schedules. The codes that contributed to this theme included giving priority to studio lessons, flexibly planning and setting goals, and effectively using practice time.

Although participants participated in various music-related activities such as performing in ensembles and serving as a teaching assistant, they gave priority to what they were working on in studio lessons when organizing their practice routines. Jack, a cello player, believed that he could not go over every facet of his musicianship in each 
practice session. Therefore, "it [practice routine] has to do with what I want to do in my lesson, the next week, and what my teacher asked me to do. So, I always want to cover that first and foremost" (interview). This perspective was echoed by Sarah, an oboe player, who said:

I tend to schedule my practice session around whatever I'm working on [in] my lesson. So if I'm working on a rapid repertoire that has a lot of chromatic runs or something like that, I'll base my practice session around that. (interview)

Sarah also provided a description of her practice during the videotaped practice session: This is actually an exercise that my professor [and I], we've been working on in my lessons where it's a dynamic exercise, so I work on softer attacks and then build into a forte and then introduced by vibrato, and then reduce. (videostimulated recall)

Participants created flexible practice plans with goals and adjusted them according to their actual needs. Dan, a tuba player, said that "I have used practice logs...I haven't really used them recently. I might write down like a couple of things [goals], but it's never like today I did this and tomorrow I'm doing that" (interview). Jack explained how he set goals for this video-recorded practice session:

I always have mental goals for just one thing I want to get done. Early on in that video, I want to know my rhythms, fingerings, bowings, and get the basics done so that I can improve it a bit more the next time...Like for the most recent thing we watched, I wanted to get the intonation a bit better. And for the other solo, we watched that one; I had a few specific goals, I guess. But I wanted to get more comfortable running through some of the more difficult parts in it. (interview) 
Although the practice session that Dan recorded was representative of his typical practice routines, he stated that "I tend to do at least some of those things every day. And I might do different things...I think it's just dependent on the day [what I need to work on]." Mary, a percussion player, expressed the same opinion: "It [the organization of the practice routine] really depends like if I'm learning a piece or if I'm perfecting a piece because those practice sessions look a lot different" (interview).

Participants efficiently used practice time and shaped practice routines according to the individual's habits and needs. Mary was used to blocking off one section of practice each day and practicing late at night after having all other things done. However, Sarah often practiced twice a day with breaks to relax and accomplished other tasks in between her practice sessions. She also reported that "I tend to do afternoon, and sometimes night, [but] I don't really like to practice much in the mornings" (interview). Jack also mentioned allocating time during his practice session:

I think that at that point, I just decided it would be best to move on to most effectively using the time that I had that day...I figured it'd be okay to move on at that point because I basically accomplish my goal for the day with that piece. (video-stimulated recall)

Furthermore, he described that "I usually go through them [scales, etudes, and pieces] and decide at some point that it's fine. There are other things I need to get to [complete]" (interview).

A task-oriented approach played a dominant role in the organization of participants' practice routines. They prioritized studio lessons and spent much time practicing the pieces they had been assigned by their instructors. Moreover, participants 
exhibited self-regulation skills similar to other collegiate musicians who also applied metacognitive thinking, planning and setting goals, and time management while organizing their practice sessions (Araújo, 2016; Nielsen, 2001). Although planning practice sessions has been recommended by researchers (Barry, 1992; Byo \& Cassidy, 2008; Kostka, 2002), an unchanging routine may impair practice quality and efficiency (Byo \& Cassidy, 2008), especially considering that graduate instrumentalists in this study indicated that they had to participate in various daily musical activities such as ensemble rehearsals and performances. Therefore, organizing a practice routine that can be flexibly adjusted based on tasks and contexts such as available practice time, short-term goals, and individual needs should be taken into account in response to instrumentalists' busy schedules.

\section{Theme Two: Solution-Oriented Approaches}

Participants learned various practice strategies and adopted them based on the need to solve problems. The theme solution-oriented approaches was identified to indicate that participants commonly applied analytic strategies, combined multiple practice strategies to solve a problem, and used practice tools during their practice sessions.

The application of analytic strategies was associated with identifying problems and deciding optimal strategies for improving performance. All participants reported their ability to identify difficult practice sections (questionnaire). Sarah stated that "the first time playing through it [etude] just kind of putting a toe in the water to see what I know, I'm gonna have to fix, and what's not such an issue. So just kind of testing it out" (videostimulated recall). Similarly, when Mary worked on one difficult measure, she explained: 
I'm playing with the rhythms... I'm on the way, searching for my tempo. I heard the inconsistency in my left hands there with the double laterals. It's kind of like mixing together the technical challenges with the accuracy challenges. That's why this passage is difficult for me at least. (video-stimulated recall)

Jack shared his skill of experimenting, referring to the process by saying "think of all the possible ways to do something [e.g., fingering, bowing, or tuning] and how to decide what the best one is" (interview), which stimulated him to listen critically to and think of what he played. For example, "I'm experimenting with bows at that point to look for the most comfortable way to play that passage" (video-stimulated recall).

After identifying challenging sections, participants tended to apply multiple strategies to solve problems. Mary worked on three measures in her practice video, and the most frequently applied practice strategies across the practice session were isolation, repetition, and tempo variation. Similarly, when working on a scale exercise, Sarah said: I broke the arpeggio up into rhythmically blocked sections, where I do in groups of three. And then I think I do fast and slow, alternating those rhythmic patterns until I can get it to speak a little better. That was the goal. (video-stimulated recall)

Isolating the difficult section and then combining repetition and slow practice was frequently applied by Jack when figuring out a challenging passage: "You'll see that I'll repeat that [section] a couple of times, especially the higher position stuff at a slower tempo where I know actually to focus on the intonation" (video-stimulated recall). In another piece, he further described that "[I play] just a little bit slower and repeat [this 
section]. There's a really quick shift, which makes it kind of hard to get in the right place at the right time" (video-stimulated recall).

Using practice tools was helpful for participants to find problems and evaluate progress. Although using the metronome was reported as the most commonly-applied practice tool used by all four participants while practicing (questionnaire), participants also used recordings, a tuner, and a breathing tube to assist practice. Mary believed that videotaping her practice could be used for evaluating progress: "I do videotape myself sometimes and watch it. So I can see what it [practice outcomes] looks like" (interview) as well as for identifying problems. For example, while watching the practice video, she commented:

My wrist looks way too high off the keyboard. I'm wondering if my keyboard needed to be raised a little bit. It looks too low right now. That's why you should videotape yourself...If they're at a high [position], it affects your accuracy...So I think raising the keyboard like half an inch would make a difference potentially. (video-stimulated recall)

Sarah used a tuner to check her intonation: "As I play, I really tend to get sharp... So I catch myself [check intonation] at a point to make sure that I'm still in tune...because I don't want to form bad habits" (video-stimulated recall). Breath Builder is a visual tool that Dan uses to practice his breathing:

It is just a ping pong ball in the tube. I use it to kind of build lung capacity and make sure I'm breathing the way I'm supposed to... When I put the tube in my mouth...if I'm exhaling a good breath, it's gonna keep the ball up and not gonna sink. (video-stimulated recall) 
The Breath Builder enabled Dan to observe how his breathing was rather than "thinking about weird things the body might be doing or not doing" (interview).

Participants in this study used various practice strategies and solution-oriented practice approaches. With more than 10 years of performance experience, on average, participants were more likely to adjust the application of practice strategies to solve problems such as experimenting with different approaches to solve performance problems. Consistent with previous research findings, participants isolated small music segments and gradually added more measures (Graaff, 2014; Tan \& Miksza, 2019). Analytic strategies, such as self-monitoring and self-evaluation, also were adopted by participants during practice and have been identified by researchers as critical skills for musicians when keeping track of practice effectiveness, examining practice progress, and avoiding repetitive errors (McPherson \& Renwick, 2001; Nielsen, 2001). Similar to previous investigations, using a metronome and a tuner helped participants pinpoint and solve problems (Graaff, 2014; Harnum, 2013). In sum, participants in the current study adopted appropriate practice strategies in response to solving specific problems that they identified as a result of improving practice efficiency.

\section{Theme Three: Mixed Motivations}

Participants were both intrinsically and extrinsically motivated to practice. Enjoying making music, strengthening fundamentals, and preparing for lessons were codes that contributed to the mixed motivations theme.

Enjoyment while playing their instruments and making progress motivated participants to practice. Mary expressed that "I like practicing and getting better [at the instrument]" (interview). Dan shared the same thoughts: "I enjoy making music. I enjoy 
getting better at the instrument...It makes me feel satisfied for at least a little bit that I can see myself progressing. If I don't see myself progressing, that motivates me even [practice] more" (interview). Responses from participants' questionnaires (see Table 2) further supported this statement, indicating that they were motivated by intrinsic motivation and enjoyed playing their instruments.

Table 2

Responses to the Practice Motivation Subscales in Order from Highest to Lowest Mean Ratings

\begin{tabular}{lll}
\hline \multicolumn{1}{c}{ Statement } & $M$ & $S D$ \\
\hline Intrinsic Motivation: Growth & & \\
I practice my instrument because I enjoy accomplishing personal goals. & 5.00 & 0.0 \\
$\begin{array}{l}\text { I practice my instrument because I enjoy a challenge. } \\
\text { I practice my instrument because the skills that I develop are really }\end{array}$ & 4.75 & 0.50 \\
& 4.75 & 0.50 \\
interesting to me. & 4.50 & 0.58 \\
$\begin{array}{l}\text { I enjoy practicing because I like solving problems. } \\
\text { I enjoy practicing my instrument because it allows me to express myself. }\end{array}$ & 4.25 & 0.96 \\
$\begin{array}{l}\text { Extrinsic Motivation: Avoid Failure } \\
\text { I practice my instrument because I do not want my teacher to think that I } \\
\text { am a poor student. }\end{array}$ & 4.50 & 0.58 \\
$\begin{array}{l}\text { I practice my instrument because I do not want to receive criticism from } \\
\text { my teacher. }\end{array}$ & 4.25 & 0.96 \\
$\begin{array}{l}\text { Extrinsic Motivation: Approach Success } \\
\text { I practice my instrument because I want my teacher to think that I am a } \\
\text { good musician. }\end{array}$ & 4.00 & 0.82 \\
$\begin{array}{l}\text { I practice my instrument because I want to receive high grades from my } \\
\text { teachers. }\end{array}$ & 3.25 & 0.96 \\
\hline Note. $N=4$. Scale = 1 (Strongly disagree) to 5 (Strongly agree). & & \\
\hline
\end{tabular}

Strengthening fundamentals to improve expertise motivated participants to practice. Sarah and Dan spent time practicing fundamentals such as buzzing, tone, and scales. They believed that building fundamentals are necessary for expertise 
development. Sarah practiced scales and an etude in the video: "The 30-minute session is really just to build fundamentals and work on little things that are meant to build skills...It is something that I scaffold with, when I'm practicing" (interview). Likewise, Dan focused on fundamentals during his entire practice session:

I'm trying to get my fundamentals better...I spend a lot of time... do [play] a long note or maybe two or three notes... It is boring when I'm practicing it, but I feel like if I'm solidifying these notes every day here and there, it'll pay off later like dividends...If I want to be successful, I need to work and turn my weaknesses into strengths. That's kind of how I think of the fundamental building. I want to be stronger over time. (interview)

Aside from intrinsic motivation, extrinsic motivation such as getting ready for lessons and performances also played an important role in motivating participants' desire to practice. Jack enrolled in an ensemble and stated that "we had a lot of deadlines this semester. So making sure I was ready [for performance] definitely motivated [my practice]" (interview). Mary expressed her perspectives regarding practice motivation: My lesson with my professor is the biggest one, probably...A lot of it would be external motivation. So concerts, performances, [and] auditions. I'm always like kind of thinking about the next step. Like if I don't practice now, I'm never going to get into a doctoral program. I'm never going to get a job or whatever. (interview)

Dan described similar reasons: "I want to be able to get a job. I want to be competitive. And that definitely motivates me to practice" (interview). Sarah sometimes was inclined 
to tell her professor what she planned to show next week because "that way, I can selfmotivate to make sure that I get that done because my professor expects it" (interview).

Participants' instrumental practice motivation included both intrinsic and extrinsic influences. Consistent with the findings of Hallam (1995) insofar that intrinsic and extrinsic motivation may coexist, participants in the current study expressed their enjoyment for practicing, desire for improving expertise by focusing on fundamentals, and motivation by getting ready for lessons and performances. It is possible that practicing pieces to get ready for lessons allowed participants to perform a varied repertoire and explore music that interested them, a process that likely contributed to their intrinsic motivation. Because Diaz (2010) also found that graduate instrumentalists did not differ greatly in intrinsic and extrinsic motivation in instrumental practice, these orientations are not necessarily dichotomous, even if individuals seem to exhibit one factor more than the other.

\section{Theme Four: External Challenges}

Factors that hindered participants' practice motivation mainly were from external challenges. The codes that contributed to this theme included changing social contexts, pressure from assignments, and practice environment.

Due to the impact of Covid-19, there were many challenges relating to practice time, room availability, and psychological state. Participants admitted that they cut down practice time compared to the past. Due to the two-hour time limitation for use of practice rooms imposed within the School of Music, Dan and Jack had to take instruments back to their apartments. Jack said that “this semester, I haven't practiced hours on it [cello] as much because of the limited [practice] room availability...I practice a bit in my 
apartment. I usually do it quietly...to kind of get some extra time" (interview). Dan stated that "even though I told my neighbors I play the tuba, I'm definitely not gonna start before 10 am and I won't play past $6 \mathrm{pm}$...I do try to practice every day" (interview). However, compared with Jack and Dan, Mary was not as fortunate and was without her instruments for four months. She described her experience:

I couldn't practice because I didn't have instruments. So for months, I didn't have a marimba and all the things [i.e., timpani, snare drums] that I normally play. I didn't have any of them. Because I had to be home and the school wasn't open. That was really hard. When I came back, and I haven't touched these instruments in months, I feel so behind...I feel disconnected. I was kind of sad to start again. It took time to build up that motivation again, for sure...I felt intimidated and kind of unmotivated and behind after so much time off. (interview)

Course assignments, rehearsals, and jobs diverted participants' attention and shortened the length of time they practiced. Jack accepted the interview around the midterm exam week and said that "I have a big paper to write. I've been spending a lot of time on that...I want to get work done...So, I'd say other classes can hinder my practice time" (interview). Mary mentioned that "I really need to find time to practice. That's going to be my main priority. But I do have a TA [teaching assistant job] that takes up time...Homework, performances, or rehearsals, that kind of things [take up my practice time]" (interview). Consequently, she tended to "go submit the assignment or go answer all emails first" and then focused on her practice session (interview). Dan indicated that stress from schoolwork such as exams and tests affected his practice motivation. He commented that "what will make me cut practice is I'm stressed out about classes, or I 
fall behind. When I'm trying to focus on the practicing, but I'm still thinking about other things I have to do" (interview).

The practice environment affected practice efficiency and motivation. Sarah described her preferences:

If I can practice at home, I will. If I can practice even just in a hall, I'll do that as well, like in a performance area, where I can be a little more comfortable [than practice rooms] and not feel like I'm in a tiny box... Because all practice rooms are the same. They're all kind of bland. It's very reflective...I don't really enjoy being in the room. (interview)

Moreover, she explained how the rainy weather hindered her practice progress:

If it's super rainy, I know that my reeds are going to be different because they change with the weather. It's going to be a difficult practice session that I spend more time making reeds and less time playing. And so that kind of hinders my motivation a little bit...Because I know it's going to be more tiring, [and] it's not going to be as productive as I want. (interview)

Changing social contexts, pressure from schoolwork, and undesired practice environment negatively influenced participants' instrumental practice. Covid-19 has changed traditional learning contexts and has been challenging to many college students (Adedoyin \& Soykan, 2020; Wang et al., 2020). Because decisions had to be made quickly by college leaders under the pandemic to prevent infection and transmission on campus (Gardner, 2020), participants were required to shorten their practice time and even lost the opportunity to practice for months in response to these changes. This negatively affected some graduate students' mental health, and resulted in low well- 
being, stress, anxiety, and depression (Zahneis \& June, 2020). When participants were allowed back on campus, the perception of disconnection and anxiety hindered their motivation to practice. Moreover, participants indicated that practicing in an undesired environment might hinder practice efficiency and influence psychological state.

Consonant with the findings of Jørgensen (1996), other enrolled courses and individual schedules were factors that shortened the length of practice time. Although taking other academic courses helped to enrich professional knowledge, working on course assignments may occupy practice time. As a result, setting aside time to practice and completing schoolwork before practicing were adopted as ways to eliminate distractions and ensure practice efficiency.

\section{Conclusions and Limitations}

I investigated four graduate instrumentalists' practice habits and motivation orientations in this study. Four themes emerged: task-oriented practice routines, solutionoriented approaches, mixed motivations, and external challenges. Some results of the current study were consistent with prior research, but there also were unique findings due to different learning contexts caused by Covid-19.

Findings indicated that participants organized their practice sessions in a taskoriented manner such as giving priority to studio lessons, flexibly planning and setting goals, and effectively using practice time. In contrast to the findings of previous investigations that advanced musicians were less likely to effectively use practice time and engage in practice planning (Jørgensen, 1998; Nielsen, 2004), graduate instrumentalists in the current study exhibited self-regulation skills including decision making, setting goals, and time management. Consistent with the suggestions of Byo and 
Cassidy (2008), participants were inclined to flexibly plan practice sessions in response to available practice time. Because graduate instrumentalists in this study participated in various music-related activities, flexible planning of practice routines should be recommended by instrumental instructors, who should encourage their students to give priority to their needs and short-term goals, which would contribute to their performance achievement.

Participants applied practice strategies through solution-oriented approaches to help them accomplish goals for their practice sessions. As such, they analyzed performance problems and then flexibly combined multiple practice strategies to solve these issues. Analytic strategies, including self-evaluation and self-monitoring, were implemented throughout participants' practice, contributing to pinpointing errors and evaluating the efficacy of practice (Harnum, 2013; Rohwer \& Polk, 2006). Aside from using a metronome, a tuner and a Breath Builder were also used by participants to refine technical skills and monitor practice accuracy. Participants suggested practice strategies based on the need to solve problems encountered while practicing instead of treating this process as a fixed component of instrumental practice. It seems that graduate instrumentalists had sufficient technical skills and self-regulation ability. Therefore, instrumental instructors should consider providing opportunities to encourage graduate instrumentalists to share their practice habits and performance experiences, which would be helpful to undergraduate music majors' practice efficiency and musicianship development.

I found that participants were both intrinsically and extrinsically motivated to practice. They enjoyed practicing and making progress on their instruments. Likewise, 
strengthening fundamentals was regarded as a necessary component for their expertise development. Getting ready for lessons and performances also motivated participants to practice and seemed to be an opportunity to improve expertise in preparing for their future careers. Therefore, instrumental instructors should consider teaching lessons in combination with students' career development needs, which would increase their students' intrinsic motivation to practice and contribute to well preparing for job applications.

External challenges, including the change of social contexts, practice environment, and the pressure of schoolwork, hindered participants' practice motivation. In particular, instrumentalists had to keep learning with limited resources after temporarily leaving campus during the Covid-19 pandemic, resulting in their feelings of disconnection and anxiety. Given these findings, instrumental instructors and collegiate musicians should work together to talk about their challenges and needs, discuss potential solutions, and develop applicable modes to navigate the challenges inherent in remote teaching and learning.

The small number of participants and the brief amount of time for data collection are limitations of the current study. Therefore, results cannot be generalized to all graduate instrumentalists. Having opportunities to observe instrumentalists' practice sessions in person and interviewing them immediately afterward would provide more comprehensive information about their thoughts toward practice and their performance. Results of this study may spur future investigators to shorten the time interval between practice sessions and interviews in order to acquire participants' thoughts about their practice strategies more quickly. 
Practice strategies used by graduate instrumentalists from different instrumental families were examined in this current study through observing videotaped practice sessions and interviews. In the future, researchers might focus on musicians from one instrument family such as brass to further explore applied practice strategies in particular areas, thus providing more specific suggestions for teachers and students. In contrast to the findings of this current study that graduate instrumentalists adopted flexible practice plans and analytic strategies to evaluate their practice progress, Byo and Cassidy (2008) indicated that collegiate musicians applied a static and nearly identical practice routine. Furthermore, Kostka (2002) found that studio instructors and collegiate musicians did not discuss how to organize practice routines and evaluate practice plans in studio lessons. Therefore, further examinations could involve studio instructors and their students to investigate possible factors resulting in the formation of practice habits. Doing so may contribute to instructors' understanding of their students' practice needs, thus enhancing the effectiveness of teaching and learning.

In this study, I investigated graduate instrumentalists' practice habits and identified negative influences on their emotional state and practice progress caused by Covid-19. Understanding graduate instrumentalists' learning contexts and challenges during the pandemic can help studio faculty instructors support their students in the design of their practice schedules. The findings of the current study provided valuable information about graduate instrumentalists' practice routines and practice strategies. Their experience could be a reference for other instrumentalists in organizing practice sessions, improving practice efficiency, and ensuring continued progress and passion in practice and performance. 


\section{Chapter Four}

\section{Collegiate Instrumentalists' Applications of Practice Strategies and Practice Motivation}

Practice is essential for musicians to make progress. In order to practice efficiently, musicians are given suggestions by their teachers such as how much time to spend in practice and what specific technical skills should be addressed. Although time spent in practice may not predict performance achievement (Pitts \& Davidson, 2000), researchers have found a positive relationship between expertise development and practice time (Ericsson et al., 1993; Hallam et al., 2012). For example, middle school musicians' ability to describe practice techniques positively correlated with their performance achievement (Rohwer \& Polk, 2006). Many researchers have investigated practice strategies adopted by instrumentalists including repetition (Chaffin \& Imreh, 2001; Miksza, 2007), slowing down the tempo of the music (Austin \& Berg, 2006; Byo \& Cassidy, 2008), using a metronome and listening to model recordings (Miksza \& Tan, 2015; Perez, 2011), and analytic strategies such as performance evaluation and critical listening (Hamlin, 2014; Rohwer \& Polk, 2006). In addition, investigators have explored the relationship between self-regulation skills (e.g., planning and time management) and practice concentration (Araújo, 2016; Miksza, 2007). Practice motivation orientations (e.g., intrinsic and extrinsic motivation) were examined in association with time spent in practice (Hallam, 2002), performance achievement (McPherson \& McCormick, 2000), and practice persistence (Hallam, 1995). It is evident that effective practice sessions involve the interaction among time spent in practice, technical skills, and practice motivation. 
Researchers have reported mixed findings about time spent in practice and expertise development. A long-held belief among many musicians was that more time spent in practice could contribute to improving performance skills. For example, Ericsson et al. (1993) studied three groups of violinists with differing skill levels: the best violinists, good violinists, and violin players who specialized in the violin and planned to become music teachers after graduation. The best violinists reported practicing deliberately (i.e., fully engaging in an activity in an effort to improve performance) approximately 19.2 hours per week, followed by the good violinists ( $16.8 \mathrm{hr} /$ week) and the music education student violinists (9.1 hr/week). Similarly, Jørgensen (2002) found a positive relationship between conservatory students' time spent in practice and their performance level (i.e., excellent, very good, or good). In contrast to previous findings, researchers have found that performance achievement was not related to time spent in practice but rather the practice strategies used by their participants (Duke et al., 2009; McPherson, 2005). Therefore, it is necessary to describe what skills musicians address while practicing.

Repetition and slow practice are common practice strategies adopted by instrumentalists across all levels. Sixth-grade instrumentalists described skills they used for practicing a difficult piece: repetition of difficult measure(s) until correct and slow practice with a gradual tempo increase (Austin \& Berg, 2006). According to researchers' observations and students' self-report surveys, findings indicated consistently that collegiate musicians frequently worked out difficult passages by slow practice and repetition (Barry, 2007; Byo \& Cassidy, 2008; Duke et al., 2009). Professional musicians were inclined to repeat small sections interspersed with longer passages (Chaffin \& 
Imreh, 2001; Miklaszewski, 1989), and alternated between slow and fast tempos to evaluate progress and achieve goals (Graaff, 2014). As expertise develops, musicians are more likely to set explicit goals along with their repetition and slow practice rather than mechanically playing through excerpts repeatedly and leaving unsolved problems (Duke et al., 2009; Gruson, 1988; Hallam et al., 2012; McPherson \& Renwick, 2001)

Listening to recordings and utilizing a metronome have also been recommended for music practice. Although music teachers have suggested their students listen to model recordings and use a metronome while practicing, researchers have found that only a small number of students adopted these suggestions (Austin \& Berg, 2006; Perez, 2011). Consistent with previous findings, although using a metronome can improve practice efficiency, few collegiate band students reported using one during their practice sessions (Miksza \& Tan, 2015). However, Hallam et al. (2012) identified a linear relationship between grade level and the application of recordings (i.e., recording self-playing and listening to the recording, listening to model recordings) and using a metronome in precollege musicians' practice. Although using tools to facilitate performance achievement is advocated by instructors, they seem to be overlooked by many student instrumentalists.

Organizing practice sessions, including setting goals and following practice routines, can improve musicians' practice efficiency. For example, as evaluated by a panel of adjudicators, musicians in a structured practice group performed better than those in the free practice group after four practice sessions, suggesting that a highly organized practice session is an effective means of improving performance achievement (Barry, 1992). However, although studio teachers suggested their students follow a specific routine to practice, 74 of $134(55 \%)$ music majors reported that they did not do 
so (Kostka, 2002). Contrary to previous findings, Byo and Cassidy (2008) identified that most of the music education major students in their study reported using a static practice routine, but the authors recommended the design of a flexible practice routine based on individual schedules. Given students' reports of their practice routines, how to apply and alternate practice strategies has elicited discussions in different learning contexts. The use of analytic strategies (e.g., looking over music before playing and identifying difficult sections) has been associated with musicians' performance achievement and expertise development. Rohwer and Polk (2006) indicated that 32 of 65 (49\%) eighthgrade musicians used analytic strategies such as identifying difficult sections and analyzing the key or meter. As rated by band directors, analytic musicians obtained higher performance scores than those who only played through the excerpts repeatedly. In contrast, Hallam et al. (2012) found that there was no relationship between the level of musicians' expertise and their frequency of applying analytic strategies. However, analytic strategies are necessary to practice progress because they help students listen critically, evaluate performance, monitor thoughts and behavior, and improve practice efficiency (Hamlin, 2014).

Practice concentration has been found to closely relate to self-regulation ability, which refers to learners who are "metacognitively, motivationally, and behaviorally active participants in the learning process" (Zimmerman, 1986, p. 308). McPherson and Renwick (2001) conducted a longitudinal study of self-regulation in children's first three years of instrumental learning by regularly recording their practice sessions. They found that the children who exhibited a poor ability to self-regulate and were distracted during practice made the least progress on the instrument when tested during their third year of 
learning. Additionally, a negative relationship was identified between middle school musicians' level of self-regulation and their irrelevant playing behavior (i.e., practicing etudes and repertoire not included in the study) (Miksza et al., 2012). These findings indicated that self-regulation abilities improve gradually over time such that musicians can more easily set goals, plan and manage their time, and self-evaluate their skills during practice (Araújo, 2016). As a result, they can focus on practice tasks for a longer period of time.

In addition to practice strategies, motivation plays an important role in the persistence of instrumental learning. Compared with extrinsic motivation driven by external rewards such as grades and praise, intrinsic motivation driven by internal factors such as interest and enjoyment (Araújo, 2016; Ryan \& Deci, 2000) is more likely to contribute to extended periods of practice (Hallam, 2002). Schmidt (2005) found that middle and high school band students' intrinsic motivation was strongly related to time devoted to practice. However, when interviewing professional musicians, a different outcome occurred: 12 of 22 musicians maintained that they were extrinsically motivated by needing the incentive of concerts to sustain practice; five were intrinsically motivated, and the remaining five exhibited a combined motivation for daily practice (Hallam, 1995). Therefore, the disparity among musicians' motivation may be moderated by expertise. However, for pre-college musicians, intrinsic motivation should be regarded as a sign of commitment and persistence.

Although researchers have studied practice behaviors and habits used by precollege musicians (Austin \& Berg, 2006; Christensen, 2010; Hallam et al., 2012; Hamlin, 2014; Miksza, 2007; Miksza et al., 2012; Prichard, 2017; Yoo, 2020) and professional 
musicians who achieved international recognition (Graaff, 2014; Harnum, 2013), there have been few studies involving the application of practice strategies and the relationship between practice time and motivation orientations among collegiate instrumentalists (Araújo, 2016). Because these factors are associated with expertise development and may affect collegiate instrumentalists' future careers, it seems important to investigate collegiate instrumentalists' time spent practicing their primary instrument and their application of practice strategies. Music teachers could use these results to design practice strategies and routines meant to develop and refine their students' musicianship. Additionally, findings from the current study would enable collegiate instrumentalists to potentially broaden their practice skills and improve practice efficiency.

The purpose of this study was to examine collegiate instrumentalists' applications of practice strategies and their motivation to practice. The research questions included: (1) How much time do collegiate instrumentalists report practicing weekly? (2) How frequently do collegiate instrumentalists apply different types of practice strategies? (3) To what extent do motivation orientations correlate to weekly practice time?

\section{Method}

\section{Respondents}

Potential respondents in this study were collegiate instrumentalists enrolled in concert band or orchestra. For recruitment purposes, I searched the National Association of Schools of Music (NASM) website and identified 20 accredited institutions in the state of Missouri. This group of institutions represented an ideal sampling frame because the schools have similar curricula, multiple ensemble offerings, and were in the same state. However, two directors responded that there were not many students (only 12 to 14) 
enrolled in ensembles at their institutions due to the impact of Covid-19. Therefore, I expanded sampling to Kansas and Iowa - two states contiguous to Missouri with a similar population - in an effort to access additional potential participants.

A recruitment email, including Institutional Review Board-approved consent information, the purpose and description of the study, and an electronic link to the survey, was sent to 70 directors of bands and orchestras at 45 accredited institutions. (No director contact information could be found at one institution, and the department chair did not respond to an email message.) A reminder email was sent two weeks after the initial message. Fourteen directors indicated that they forwarded the recruitment email or sent the survey link to 212 potential participants in their ensembles. Forty-one respondents indicated that they were non-music majors or majors not covered in the selections, and 43 respondents did not complete the entire survey. After removing these individuals' responses, a total of 128 acceptable responses remained.

Respondents $(N=128)$ identified as male $(n=58,45.3 \%)$, female $(n=68$, $53.1 \%)$, or non-binary/third gender $(n=2,1.6 \%)$. They were pursuing a bachelor's degree $(n=100,78.1 \%)$, master's degree $(n=21,16.4 \%)$, or doctoral degree $(n=7$, $5.5 \%)$. Areas of study included music education $(n=62)$, music performance $(n=52)$, music therapy $(n=8)$, conducting $(n=4)$, composition $(n=1)$, and music history $(n=1)$. Their primary instruments included flute $(n=16)$, clarinet $(n=15)$, trombone $(n=13)$, trumpet $(n=13)$, percussion $(n=11)$, saxophone $(n=9)$, horn $(n=8)$, other $(n=8)$, oboe $(n=7)$, viola $(n=6)$, tuba $(n=5)$, violin $(n=4)$, bassoon $(n=3)$, double bass $(n=3)$, euphonium $(n=3)$, piano $(n=3)$, or cello $(n=1)$. 
Two of the 128 respondents were doctoral students whose age were 59 and 51, respectively, higher than typical college students. Considering that their demographics may skew the means of most respondents' information leading to results being misleading, I provided means, standard deviation, and median without their data included for age and years of instrumental learning but retained their remaining responses were included in the data analysis. Respondents' reported ages ranged from 17 to 35 years old $(M=20.95, S D=3.23$, Median $=20.00)$ and 3 to 25 years of instrumental learning $(M=$ $10.02, S D=3.65$, Median $=10.00$ ). They began learning their primary instrument at ages ranging from 5 to 21 years old $(M=11.19, S D=2.42)$. The mean length of reported time spent in practice was 10.38 hours per week $(S D=7.00)$, although respondents indicated that they intended to practice 14 hours per week $(S D=8.00)$. Respondents reported that they learned practice strategies from instructors $(n=123,96.1 \%)$, self-exploration $(n=$ $90,70.3 \%)$, including books, research articles, and workshops, peers $(n=87,68.0 \%)$, social media platforms ( $n=58,45.3 \%)$, such as Facebook, YouTube, and Twitter, or parents $(n=13,10.2 \%)$.

\section{Questionnaire}

In this descriptive survey study, I used a questionnaire consisting of two scales and one demographic section to collect data. One of the scales was adapted from Hallam et al. (2012) and used in my pilot study (Liu, 2021) to gauge instrumentalists' practice strategies. In this study, I added one more subscale and four items based on my pilot study (Liu, 2021). The other scale was developed by Schatt (2011) and used to investigate musicians' motivation to practice. Both scales were previously found to be valid and reliable. 
Practice Strategies Scale. In my pilot study, I adapted the 28-item scale designed by Hallam et al. (2012) by adding several items about practice concentration and organization to make the scale applicable to collegiate musicians. Two experienced music education researchers and three graduate student musicians reviewed and provided feedback on the adapted scale used in my pilot study (Liu, 2021). Based on their suggestions, I changed the wording of several items. A factor analysis indicated five items with low loadings $(\alpha<.50)$, so I removed them. The adapted scale used for analyzing data in the pilot study consisted of 23 items under five subscales and displayed good internal consistency $(\alpha=.80)$ (George \& Mallery, 2002).

In the current study, I further adapted the scale used in my pilot study (Liu, 2021). The purpose of this adaption was to include more items relating to practice strategies in order to investigate specific and complete applications of technical skills among collegiate instrumentalists. Specifically, I added one more subscale, "correction of errors" ( 3 items, see Appendix I for the complete scale). In addition, I included two statements used by Rohwer and Polk (2006): "I can recognize errors while practicing" (adoption of systematic strategies); "I conduct silent practice" (adoption of systematic strategies); and another two statements from Pintrich et al. (1991): "I have a set practice routine" (organization); "I can stick to my practice schedule (organization)." Therefore, a total of 30 items under six subscales were used in this study. Items included: (a) adoption of systematic strategies (7 items), metronome and recordings ( 3 items), organization (7 items), concentration (4 items), analytic strategies (6 items), and correction of errors (3 items). Items were rated according to the frequency of applying these practice strategies on a scale from 1 (Never) to 5 (Very frequently). Based on analysis of data obtained for 
this study, the internal consistency of the scale was acceptable $(\alpha=.77)$ (George $\&$ Mallery, 2002).

Practice Motivation Scale. I used a 9-item scale by Schatt (2011) to measure respondents' motivation orientations (i.e., intrinsic and extrinsic beliefs) for music practice. This scale was originally designed to examine attitudes and beliefs of high school instrumental music students toward music practice. Schatt (2011) reported that the internal consistency of the scale was acceptable $(\alpha=.72)$. In the current study, I applied the same scale and required participants to rate their level of agreement on the following nine items under three subscales: (a) Extrinsic Motivation: Approach Success (2 items), (b) Extrinsic Motivation: Avoid failure (2 items), and (c) Intrinsic Motivation: Growth (5 items) using a Likert-type scale from 1 (Strongly disagree) to 5 (Strongly agree). The internal consistency of the scale based on the data from the current study was close to that obtained by Schatt (2011) and considered acceptable $(\alpha=.70)$ (George \& Mallery, 2002). See Appendix $\mathbf{J}$ for the practice motivation scale.

Demographic Items. I included a demographic section consisting of 11 items to collect respondents' information such as their gender, degree, age, major, and weekly practice time (see Appendix K).

\section{Procedures}

To establish content validity, two music education researchers with approximately 23 years of collegiate teaching experience were asked to review the questionnaire. Edits and revisions that were made based on their suggestions included modifying the sequence, layout, and wording of the items in order to make them more concise and easy to answer. Three advanced musicians who all had more than 15 years of experience on 
their primary instrument also provided feedback about the questionnaire. According to their suggestions, minor wording changes were made on several items.

I used Qualtrics, an online survey program, to create and distribute the questionnaire for this study. The first page of the survey contained the purpose and description of this study, a notice of consent, and the Institutional Review Board and researcher's contact information (see Appendix H). The survey consisted of three sections designed to gather information regarding instrumentalists' (a) application of practice strategies, (b) practice motivation, and (c) demographic information. On average, the survey took approximately 6 minutes to complete.

\section{Results}

I calculated instrumentalists' reported actual and intended weekly practice time by instrument family and degree (see Table 3$)$. Pianists $(M=29.33, S D=10.07)$ reported that they practiced more hours than percussionists $(M=11.68, S D=8.59)$, brass $(M=$ $10.98, S D=6.86)$, other instrumentalists $(M=10.31, S D=5.99)$, woodwind $(M=9.14$, $S D=5.19)$, and string players $(M=7.93, S D=6.23)$. Pianists $(M=40.0, S D=0.00)$ reported that they intended to practice more hours than percussionists $(M=14.64, S D=$ 6.33), other instrumentalists $(M=14.56, S D=6.25)$, brass $(M=14.12, S D=7.85)$, woodwind $(M=12.75, S D=6.43)$, and string players $(M=11.71, S D=7.35)$. Moreover, graduate instrumentalists $(M=13.13, S D=8.25)$ reported that they spent more hours in weekly practice than undergraduate instrumentalists $(M=9.61, S D=6.44)$. Similarly, graduate instrumentalists $(M=17.05, S D=10.09)$ intended to practice more hours than undergraduate instrumentalists $(M=13.15, S D=7.13)$. It is notable that all pianists 
reported that they intended to practice 40 hours each week. $95.31 \%$ of respondents reported that they spent less time in weekly practice than they intended to do.

\section{Table 3}

Means and Standard Deviations of Respondents' Reported Actual and Intended Weekly

Practice Time

\begin{tabular}{lccccc}
\hline \multirow{2}{*}{ Variable } & $n$ & \multicolumn{2}{c}{ Actual practice hours } & \multicolumn{2}{c}{ Intended practice hours } \\
\cline { 3 - 6 } & & $M$ & $S D$ & $M$ & $S D$ \\
\hline Instrument Families & & & & & \\
$\quad$ Piano & 3 & 29.33 & 10.07 & 40.0 & 0.0 \\
Percussion & 11 & 11.68 & 8.59 & 14.64 & 6.33 \\
Brass & 42 & 10.98 & 6.86 & 14.12 & 7.85 \\
Other (e.g., organ) & 8 & 10.31 & 5.99 & 14.56 & 6.25 \\
Woodwinds & 50 & 9.14 & 5.19 & 12.75 & 6.43 \\
$\quad$ Strings & 14 & 7.93 & 6.23 & 11.71 & 7.35 \\
Degree & & & & & \\
$\quad$ Graduate & 28 & 13.13 & 8.25 & 17.05 & 10.09 \\
$\quad$ Undergraduate & 100 & 9.61 & 6.44 & 13.15 & 7.13 \\
\hline
\end{tabular}

Note. $N=128$.

The first section of the questionnaire was the Practice Strategy Scale.

Respondents were asked to choose the practice strategies and skills that they used on a Likert-type scale anchored by 1 (Never) to 5 (Very frequently). I calculated a mean and standard deviation for each item and subscale. Results indicated that respondents more frequently applied systematic strategies $(M=3.91, S D=0.89)$ while practicing than correction of errors $(M=3.74, S D=0.90)$, metronome and recordings $(M=3.57, S D=$ $0.93)$, concentration $(M=3.37, S D=1.01)$, analytic strategies $(M=3.29, S D=0.97)$, and organization $(M=2.95, S D=1.16)$. Descriptive statistics for all subscales and items are presented in Table 4. 


\section{Table 4}

Means and Standard Deviations of Respondents' Applied Practice Strategies Ratings

\begin{tabular}{|c|c|c|}
\hline Scale & $M$ & $S D$ \\
\hline Systematic strategies & 3.91 & 0.89 \\
\hline I can recognize errors while practicing. & 4.45 & 0.63 \\
\hline I practice difficult sections over and over again. & 4.28 & 0.69 \\
\hline $\begin{array}{l}\text { When I make a mistake, I practice the section where I went wrong } \\
\text { slowly. }\end{array}$ & 4.04 & 1.05 \\
\hline I mark things on the part to help me when practicing. & 4.00 & 1.05 \\
\hline I learn by playing slowly to start with and then gradually speed up. & 3.99 & 0.86 \\
\hline I practice small sections of the pieces I am learning. & 3.98 & 0.86 \\
\hline I conduct silent practice (fingering) without making sound. & 2.62 & 1.07 \\
\hline Correction of errors & 3.74 & 0.90 \\
\hline I stop and correct wrong notes before moving ahead with my practice. & 3.83 & 0.83 \\
\hline $\begin{array}{l}\text { I can correct errors immediately without the instructor having to } \\
\text { mention them. }\end{array}$ & 3.73 & 0.83 \\
\hline I mark my mistakes to help correct them in the future. & 3.66 & 1.05 \\
\hline Metronome and recordings & 3.57 & 0.93 \\
\hline I practice with the metronome. & 4.05 & 0.89 \\
\hline I listen to recordings of other advanced musicians. & 3.98 & 0.91 \\
\hline I record my playing and listen to the recording. & 2.67 & 1.00 \\
\hline Concentration & 3.37 & 1.01 \\
\hline $\begin{array}{l}\text { If others interrupt me when practicing, I can immediately } \\
\text { reconcentrate on my practice. }\end{array}$ & 3.46 & 1.03 \\
\hline $\begin{array}{l}\text { Information from my smartphone may distract my attention when } \\
\text { practicing. }\end{array}$ & 3.37 & 1.08 \\
\hline I find it is easy to concentrate when I practice. & 3.34 & 0.90 \\
\hline $\begin{array}{l}\text { After browsing information from my smartphone, I can immediately } \\
\text { reconcentrate on my practice. }\end{array}$ & 3.32 & 1.02 \\
\hline Analytic strategies & 3.29 & 0.97 \\
\hline I am able to identify difficult sections. & 4.46 & 0.59 \\
\hline I try to get an overall idea of a piece before I practice it. & 3.77 & 0.94 \\
\hline $\begin{array}{l}\text { I analyze the differences of recordings between my performance and } \\
\text { other musicians. }\end{array}$ & 3.08 & 1.23 \\
\hline I think about the interpretation of the piece before I start practicing it. & 2.99 & 1.06 \\
\hline $\begin{array}{l}\text { I work things out just by looking at the music and not playing (i.e., } \\
\text { mental practice). }\end{array}$ & 2.82 & 1.05 \\
\hline I analyze the structure of a piece before I learn to play it. & 2.64 & 0.94 \\
\hline Organization & 2.95 & $\mathbf{1 . 1 6}$ \\
\hline I begin each practice session with warm-ups. & 3.96 & 1.11 \\
\hline I can stick to my practice schedule. & 3.13 & 1.16 \\
\hline I have a set practice routine. & 3.12 & 1.16 \\
\hline
\end{tabular}




\begin{tabular}{lcc}
\hline \multicolumn{1}{c}{ Scale } & $M$ & $S D$ \\
\hline I begin my practice with scales. & 2.95 & 1.29 \\
I begin my practice with etudes. & 2.53 & 1.07 \\
I make a list of what has to be practiced. & 2.51 & 1.18 \\
I review what I practiced at the end of my practice session. & 2.46 & 1.14 \\
\hline
\end{tabular}
Note. $N=128$. Scale $=1$ (Never) to 5 (Very frequently).

The second section of the questionnaire used the Practice Motivation Scale to examine respondents' practice motivation orientations. Respondents were asked to choose practice attitudes and beliefs that best represented them on a Likert-type scale anchored by 1 (Strongly disagree) to 5 (Strongly agree). I calculated means and standard deviations of all practice motivation orientation items and subscales. Results indicated that collegiate instrumentalists more frequently exhibited Intrinsic Motivation: Growth $(M=4.36, S D=0.85)$, followed by Extrinsic Motivation: Avoid Failure $(M=3.80, S D=$ 1.28) and Extrinsic Motivation: Approach Success $(M=3.72, S D=1.20)$. Descriptive statistics for all subscales and items are presented in Table 5. 


\section{Table 5}

Means and Standard Deviations of Respondents' Practice Motivation by Subscale

\begin{tabular}{lcc}
\hline \multicolumn{1}{c}{ Statement } & $M$ & $S D$ \\
\hline Intrinsic Motivation: Growth & $\mathbf{4 . 3 6}$ & $\mathbf{0 . 8 5}$ \\
I practice my instrument because I enjoy accomplishing personal goals. & 4.64 & 0.66 \\
I practice my instrument because the skills that I develop are really & 4.49 & 0.79 \\
interesting to me. & & \\
I practice my instrument because I enjoy a challenge. & 4.36 & 0.92 \\
I enjoy practicing my instrument because it allows me to express myself. & 4.34 & 0.86 \\
I enjoy practicing because I like solving problems. & 3.97 & 1.04 \\
Extrinsic Motivation: Avoid Failure & $\mathbf{3 . 8 0}$ & $\mathbf{1 . 2 8}$ \\
I practice my instrument because I do not want my teacher to think that I & 4.05 & 1.20 \\
am a poor student. & & \\
I practice my instrument because I do not want to receive criticism from & 3.55 & 1.35 \\
my teacher. & & \\
Extrinsic Motivation: Approach Success & $\mathbf{3 . 7 2}$ & $\mathbf{1 . 2 0}$ \\
I practice my instrument because I want my teacher to think that I am a & 3.95 & 1.08 \\
good musician. & & \\
I practice my instrument because I want to receive high grades from my \\
teachers
\end{tabular}

I conducted correlation analyses to examine relationships between respondents' practice motivation, practice time, and age. The Spearman's rho test was used to calculate correlations because the data violated the assumption of normality needed to use Pearson's test. Results indicated a significant positive correlation between Extrinsic Motivation: Approach Success and Extrinsic Motivation: Avoid Failure, $r(126)=.57, p$ $<.01$. Weekly practice hours were negatively correlated with Extrinsic Motivation: Avoid Failure, $r(126)=-.25, p<.01$, but positively correlated with Intrinsic Motivation: Growth, $r(126)=.39, p<.01$. Moreover, there was a negative relationship between respondents' age and Extrinsic Motivation: Avoid Failure, $r(126)=-.17, p<.05$. Complete statistical information is presented in Table 6. 


\section{Table 6}

Spearman's Rho Correlations for Respondents' Practice Motivation, Practice Time, and Age

\begin{tabular}{lcccc}
\hline \multicolumn{1}{c}{ Variable } & 2 & 3 & 4 & 5 \\
\hline 1. Extrinsic Motivation: Approach Success & $.57^{* *}$ & -.12 & -.12 & -.10 \\
2. Extrinsic Motivation: Avoid Failure & & -.12 & $-.25^{* *}$ & $-.17^{*}$ \\
3. Intrinsic Motivation: Growth & & & $.39^{* *}$ & .07 \\
4. Weekly practice hours & & & & .02 \\
5. Age & & & 1.00 \\
\hline
\end{tabular}
Note. ${ }^{*} p<.05 .{ }^{* *} p<.01$.

\section{Discussion}

The purpose of this study was to examine collegiate instrumentalists' applications of practice strategies and their motivation orientations to practice. The first research question was designed to investigate collegiate instrumentalists' time spent in practice according to different instrument families, degree levels, and differences between actual and intended practice time. According to respondents' self-reports, results indicated that pianists spent more time in practice than percussion, brass, other instrumentalists (e.g., organ), woodwind, and string players, respectively. However, even though previous investigations also showed that pianists/keyboard players practiced the most, string players had been found to spend more time in practice than brass and woodwind players, respectively (Hallam et al., 2020; Jørgensen, 2002). The results of the current study may be due to unequal sample sizes across these instrument families, such as including three pianists and 42 brass players. Moreover, the differences in the findings may also be attributable to respondents' different majors and degrees. Thus, their motivation and opportunity to practice might be different. For example, music education majors may participate in student teaching in their senior year, so they do not have as much time to 
practice compared to music performance majors. More specific findings may arise from research that focuses on one major with specific grade levels when examining instrumentalists' practice time (Byo \& Cassidy, 2008).

The graduate instrumentalists in this study reported that they spent more time in practice than did the undergraduate instrumentalists. This result is similar to those from previous studies in which increases in musicians' time spent in practice was associated with higher levels of expertise (Ericsson et al., 1993; Hallam et al., 2012; McCormick \& McPherson, 2003; Sloboda et al., 1996). Because advanced musicians practice more complicated technical exercises and pieces than novice musicians, they need to extend practice time to accomplish increasingly difficult tasks (Hallam et al., 2012).

Furthermore, top-ranked musicians tend to spend more time on error correction by varying tempos and avoid leaving problems unsolved while practicing (Duke et al., 2009). Therefore, undergraduate instrumentalists should use practice sessions to identify and address the mistakes rather than fixating on how much time is spent in practice when evaluating accomplishment.

Most participants' reported responses showed that their time spent practicing was less than the amount of time they intended. As suggested by Nielsen (2004), it is possible that they did not use "management strategies such as setting aside blocks of time to practice, ensuring effective use of the practice time, organizing the study environment, and committing oneself to complete practice goals" (p. 426). The differences found between actual and intended practice time could be due to additional coursework. For example, collegiate instrumentalists may spend longer time than they planned to complete course assignments or prepare for examinations, resulting in shortened practice 
time. Cultivating the ability to properly plan individual schedules and practice time could improve musicians' practice efficiency and become a fundamental factor contributing to performance achievement (Bonneville-Roussy \& Bouffard, 2015; Hallam, 1998).

Respondents reported that they used systematic practice strategies most frequently, followed by error correction techniques, using a metronome and listening to recordings, concentration control, analytic strategies, and the organization of practice sessions. Similar to previous investigations, systematic strategies (i.e., slowing down tempos, practicing small sections), error detection and correction techniques, and using a metronome were found to be common and essential technical skills used by collegiate musicians (Barry, 2007; Byo \& Cassidy, 2008; Miksza, 2010). This is not surprising because instrumentalists have often been taught these strategies before college (Petersen, 2018) and frequently use them while practicing (Austin \& Berg, 2006; Miksza, 2007). However, respondents also reported their infrequent use of analytic strategies and organizing practice sessions. This may be due to insufficient metacognitive and selfregulation skills such as planning, monitoring, and self-evaluation (Araújo, 2016; Bonneville-Roussy \& Bouffard, 2015; Miksza et al., 2012). Considering that teachers and their students rarely discussed how to design individual practice plans and evaluate their effectiveness (Kostka, 2002) or how to develop metacognitive skills in lessons (Concina, 2019), instrumental instructors should consider providing self-regulation instruction on concentration control, self-evaluation, and goal setting, due to their importance in optimizing their students' practice habits (Miksza, 2015).

Practice Motivation Scale results indicated that collegiate instrumentalists were more motivated by intrinsic factors than extrinsic factors. Specifically, they enjoyed 
accomplishing goals, overcoming challenges, and expressing themselves musically while practicing. These results were similar to previous findings that intrinsic motivation is driven by individual interest (Moder, 2013; Ryan \& Deci, 2000) and is rated higher than extrinsic motivation among musicians (Diaz, 2010). However, it is possible that additional extrinsic factors that were not included in the scale influenced collegiate instrumentalists' practice motivation. For example, practice may be motivated by being more competitive in the job market than peers or acquiring external rewards such as approval from others (Ryan \& Deci, 2000). Interviewing collegiate musicians from different years of study and instrument families may expand our understanding of how practice motivation affects instrumental practice within specific contexts. In addition, the findings of these interviews may prove helpful for future practice motivation scale exploitation. Insights into collegiate instrumentalists' motivation preferences could allow instructors to know their students' psychological needs, thus contributing to course designs that meet these needs, improve the effectiveness of teaching and learning, and encourage their students' music participation (Diaz, 2010; Yoo, 2020).

Collegiate instrumentalists' practice motivation was associated with weekly practice time and age. Results indicated that respondents who were more motivated by intrinsic motivation were more likely to increase their time spent practicing. This result is consistent with previous findings among middle and high school band students (Schatt, 2011; Schmidt, 2005). Although time spent in practice is not the sole determinant of performance expertise, it may predict performance achievement (Jørgensen, 2002), especially when combining effective practice strategies (Bonneville-Roussy \& Bouffard, 2015). Therefore, developing musicians' intrinsic motivation by providing positive 
feedback (Hruska, 2011; Sandene, 1997) and promoting perceptions of competence (i.e., the need to produce desired outcomes and to experience mastery) and relatedness (i.e., the need to feel connected to others) may result in lengthened practice time and contribute to better performance outcomes. Additionally, respondents' Extrinsic Motivation: Avoid Failure was negatively correlated with practice time. Perhaps focusing too much on the attitudes of teachers (i.e., I do not want my teachers to think that I am a poor student) is stressful for musicians, resulting in feelings of boredom and anxiety, or the desire to discontinue their practice (Driscoll, 2009). I also found a negative relationship between respondents' age and Extrinsic Motivation: Avoid Failure. It seems possible that as age increases, collegiate instrumentalists were less likely to worry about failure because of the accumulation of performance experience and technical skills. Future investigations could explore the relationship between age, year of study, performance experience, and practice motivation orientations to provide detailed explanations.

The generalizability of this study is limited by the population of respondents, relatively small and unequal sample size across these instrument families, and the context of the findings as shaped by Covid-19. Due to the impact of the pandemic, university faculties experienced unexpected challenges and pressure, which increased their feelings of burnout (Daumiller et al., 2021) and communication fatigue (Smith, 2020, March). This likely influenced directors who did not send recruitment emails or the survey link to the students in their ensembles. Likewise, two directors indicated that there were not many students enrolled in ensembles in Fall 2020 at their institutions, with similar situations at other institutions possibly contributing to the small number of respondents 
participating in this study. Care should be taken in generalizing these results to a specific year in school (i.e., freshman, sophomore, junior, senior) and performance medium (e.g., brass, strings, woodwinds). Additionally, all responses were self-reported (e.g., attitudes, practice time, and frequency of practice strategies' application). Although I believed that respondents answered questions truthfully, it is possible that their answers reflected modified practice habits during Covid-19 instead of regular learning contexts. Future researchers may wish to examine the application of practice strategies and practice motivation orientations in typical learning contexts with a larger sample size.

Based on the findings of this study, I propose the following recommendations for applied instrumental instructors. Because of the difference between actual and intended practice time reported by these collegiate instrumentalists, and the results indicating that they seldom analyzed and organized practice tasks, instructors should consider teaching metacognitive and self-regulation skills during studio lessons. Possible discussions might involve evaluating task difficulties and performance, setting goals and monitoring progress, and improving concentration (Hallam, 2001b). If the metacognitive dimension could be sufficiently developed, it would promote students' reflective ability and practice efficiency, contributing to improved expertise (Concina, 2019; Nielsen, 1999). According to the result indicating that respondents tended to learn practice strategies from peers, instructors should consider organizing studio seminars and including students who play different instruments that could provide opportunities for sharing performance experiences and learning collaboratively. Moreover, considering findings of previous investigations along with the results of this study, it seems reasonable to conclude that intrinsic motivation is important to music learning and closely related to mastery and 
cooperative orientations, commitment to bands, and practice time (Diaz, 2010; Schmidt, 2005). This should pique music educators' attention because if students rely heavily on external rewards to practice, it could impair their interests and practice quality (Diaz, 2010). Instructors may consider providing positive feedback (Hruska, 2011; Sandene, 1997) by using an interactive teaching style (Bolkan et al., 2011) and promoting students' perceptions of competence and relatedness (Yoo, 2020) to improve students' intrinsic motivation.

The results of the current study also suggest possible directions for future research. For example, researchers might consider using mixed methods designs so they could include studio instructors and their students by interviewing and filling out surveys to identify practice strategies they think are important and used while practicing. Findings from observation and self-report surveys may be inconsistent but can provide specific information grounded in participants' instrumental learning experiences. This method may also advance our understanding of individual differences in music learning within specific contexts. Considering that previous investigations found relationships between practice time, self-regulation practice behaviors, and performance achievement (Bonneville-Roussy et al., 2011; Miksza, 2015; Miksza et al., 2012), further examinations could add other variables such as practice motivation orientations, performance experience, and deliberate practice strategies to develop a model with a large enough sample size to provide explanations about the extent that these factors relate to each other and may predict instrumentalists' performance achievement. Results may facilitate our understanding of musicians' expertise development and serve as guides for instructors' teaching. 
According to the findings of this study, collegiate instrumentalists should consider improving organizational and analytic practice strategies. As such, it is important that instrumental instructors provide reflective modeling to their students under specific contexts, such as demonstrating a process about how to monitor and evaluate practice progress while learning a challenging passage and designing practice plans based on progress. These skills would facilitate collegiate instrumentalists' performance achievement which could increase their intrinsic motivation. In doing so, instrumentalists may develop the capability for productive practice with an ongoing process, achieve strong and independent musicianship, and continue their lifelong passion for music performance. 


\section{Chapter Five}

\section{Summary and Conclusions}

Although pre-college musicians may be aware of what to practice, they use few strategies during their practice sessions (McPherson \& Renwick, 2001; Simmons et al., 2021) and often do not organize them efficiently (Austin \& Berg, 2006; Miksza et al., 2012). As expertise develops, musicians employ helpful practice strategies such as the use of a metronome and model recordings, error detection and correction techniques, and practicing small musical passages (Hallam et al., 2012), and they extend practice time to improve performance achievement (Hallam et al., 2012; McPherson \& Renwick, 2001). Therefore, practice efficiency has the potential to be enhanced as performance experiences accumulate.

Applying effective practice strategies relates to musicians' performance achievement and practice motivation. Practicing with a self-assessment checklist (Cremaschi, 2012) and using strategies such as whole-part-whole and varying tempo can improve musicians' self-regulation and performance skills (Miksza, 2015; Prichard, 2020). Furthermore, musicians may combine self-regulation skills and effective practice strategies to optimize performances (Nielsen, 2001) and refine action plans based on personal needs (Concina, 2019; Downing et al., 2009). Previous investigations found that intrinsic motivation was associated with practice time (Austin \& Berg, 2006; McPherson \& McCormick, 2000; Schmidt, 2005), performance achievement (McPherson \& McCormick, 2000), and practice efficiency among pre-college musicians (Miksza, 2006a). However, the authors of these studies did not explore collegiate instrumentalists' 
application of practice strategies, practice time and organization, or factors motivating or hindering their practice.

\section{Research Questions and Method}

The purpose of this dissertation was to better understand collegiate instrumentalists' practice habits and motivation. Two research questions guided my study: (1) What are the practice habits (i.e., practice time, strategies, organization) of collegiate instrumentalists? (2) What practice motivation orientations do collegiate instrumentalists possess? In order to answer these questions, I completed a comprehensive literature review (Chapter 2), a qualitative descriptive study involving four graduate instrumentalists (Chapter 3), and a survey of collegiate instrumentalists (Chapter 4). The following sections highlight the major findings of these individual investigations.

\section{Major Findings}

\section{Literature Review}

Multiple factors, including practice strategies and motivation orientations, influence musicians' performance progress. Musicians learn practice strategies with their teachers and tend to focus more on practice quality than time spent in practice as musicianship develops (Duke et al., 2009; Hallam et al., 2012). Especially for beginning musicians, teachers' instructions are expected to be codified and summarized in a checklist for directing students' home practice (Barry \& Hallam, 2002). Researchers have indicated that musicians' performance achievement is related to the amount of time spent in deliberate practice (Bonneville-Roussy et al., 2011; Ericsson et al., 1993) and formal practice (Sloboda et al., 1996). Collegiate musicians can apply various practice strategies 
to improve their performance including slow practice (Barry, 2007; Byo \& Cassidy, 2008; Cremaschi, 2012; Duke et al., 2009), identifying and correcting errors (Duke et al., 2009), and using a metronome (Barry, 2007; Byo \& Cassidy, 2008). However, they may not frequently apply self-regulation skills such as time management and practice organization (Nielsen, 2004) and analytic strategies (Byo \& Cassidy, 2008) while practicing.

Motivation is related to musical achievement and musicians' effort, enjoyment, and time spent in practice (Asmus, 1994). Given the importance of motivation orientations on instrumental learning, I discussed how intrinsic and extrinsic motivation (Hallam, 2002; Schmidt, 2005), self-efficacy (McCormick \& McPherson, 2003;

McPherson \& McCormick, 2006; Zelenak, 2014), and achievement goal theory (Miksza, 2009, 2010; Nielsen, 2008; Schmidt, 2005) affect musicians' learning experiences and outcomes across expertise levels. Additionally, social influences (i.e., parental involvement, siblings' supports, peer-assisted learning) were identified as potential factors that impact pre-college musicians' instrumental learning outcomes (Creech, 2010; Fung, 2018; Johnson, 2015; Liu, 2009; Petersen, 2018; Upitis et al., 2017).

How practice strategies are applied among middle and high school musicians has been examined (Austin \& Berg, 2006; Hallam et al., 2020; Hallam et al., 2012; Miksza, 2007; Pike, 2017; Prichard, 2017; Simmons et al., 2021), but few researchers have studied collegiate instrumentalists' time spent in practice and their use of practice strategies (Bonneville-Roussy \& Bouffard, 2015; Byo \& Cassidy, 2008) and motivation orientations (Diaz, 2010; Miksza, 2010). Given that an increased understanding of collegiate instrumentalists' practice habits could help guide instructors' teaching, I 
concluded that researchers should investigate collegiate instrumentalists' frequency of applying different types of practice strategies, practice organization, and motivation orientations. Findings would also help individual instrumentalists reflect on their practice habits, potentially improving their technical skills and practice efficiency, and hopefully contribute to their professional development.

\section{Qualitative Study}

I used a qualitative descriptive design to investigate four graduate instrumentalists' practice habits and motivation orientations. Participants were master's students majoring in music performance attending a large, public research institution in the Midwest region of the United States, whose primary instruments were cello, oboe, percussion, and tuba. Data sources consisted of a videotaped practice recording, a questionnaire, video-stimulated recall, and semi-structured interview with each participant, and my researcher journal. Trustworthiness was established through data triangulation, member checking, clarifying researcher bias, and rich descriptions (Creswell \& Poth, 2016).

Graduate instrumentalists organized their practice routines with task-oriented principles. Because they participated in many music-related activities, it was common to practice multiple pieces in a single practice session. Therefore, well-organized practice sessions ensured participants completed the musical goals they had for lessons and rehearsals. Participants gave priority to their studio lessons, practicing the pieces assigned by their instructors, and then worked on other repertoire. Creating flexible practice plans with goals and adjusting them according to needs helped improve participants' practice quality. Additionally, results indicated that graduate instrumentalists tended to allocate 
practice time by combining their individual practice habits and schedules to maximize practice efficiency.

The graduate instrumentalists flexibly adopted several practice strategies to solve specific musical problems. Participants identified difficult sections and pinpointed errors while practicing and then chose optimal approaches to cope with challenges by analyzing and experimenting, which helped them to listen critically. They were inclined to apply multiple practice strategies to solve problems, such as repeating with tempo variation to work on complicated rhythmic patterns. Practice tools (e.g., recordings, a metronome, a breathing tube) were used by participants to evaluate progress, to avoid forming bad habits, and to identify errors that had never been found or were overlooked.

Findings indicated that these graduate instrumentalists were both intrinsically and extrinsically motivated to practice, but external challenges hindered their practice motivation. Participants' enjoyment of playing their instruments and desire to make progress internally motivated them to spend much time practicing. As advanced musicians, they worked on strengthening fundamentals in practice sessions to improve expertise. In addition, extrinsic motivators such as preparing for lessons, doctoral programs, and music careers influenced their desire to practice. However, external challenges negatively influenced participants' practice. For example, due to the impact of Covid-19, the graduate instrumentalists faced challenges regarding practice room availability, which resulted in reduced or lost practice time. Working on course assignments, participating in ensemble rehearsals, and having jobs shortened participants' practice time as well, and they had to arrange their schedules to set aside sufficient time for practicing. Results also indicated that practicing in undesirable environments might 
decrease participants' motivation to practice and might lead to feelings of exhaustion and lower practice efficiency. Considering that graduate instrumentalists may encounter external challenges and pressure, finding ways to help them build confidence, cope with difficulties, and flexibly arrange individual schedules should be prioritized.

\section{Survey Study}

I surveyed collegiate instrumentalists about the amount of time they spent practicing, how frequently they applied different practice strategies, and their practice motivation orientations. A recruitment email was sent to 70 directors of bands and orchestras at 45 National Association of Schools of Music-accredited institutions from Missouri, Kansas, and Iowa. Fourteen directors indicated that they forwarded the recruitment email or sent the survey link to their students. Participants $(N=128)$ responded to items that comprised three survey sections: (a) Practice Strategies Scale (30 items), (b) Practice Motivation Scale (9 items), and (c) demographic information (11 items). Respondents indicated a wide range of primary instruments, majors, and years of instrumental learning.

Respondents reported their weekly actual and intended practice time. Pianists spent more time in practice, followed by percussionists, brass, other instrumentalists (e.g., organ), woodwind, and string players. Similarly, pianists intended to practice more hours than percussionists, other instrumentalists, brass, woodwind, and string players, respectively. Graduate instrumentalists spent more hours in weekly practice and intended to practice more hours than did undergraduate instrumentalists. Findings indicated that nearly $95 \%$ of respondents actually spent less time in weekly practice than they intended. Additionally, respondents were also asked to respond to a rating scale to indicate the 
frequency of practice strategies and skills that they used. Results indicated that collegiate instrumentalists most frequently used systematic strategies, followed by correction of errors, metronome and recordings, concentration (i.e., attention control), analytic strategies, and organization.

I also investigated respondents' practice motivation orientations and its relationship with practice time and age. Collegiate instrumentalists' responses were highest for Intrinsic Motivation: Growth, followed by Extrinsic Motivation: Avoid Failure and Extrinsic Motivation: Approach Success. Additionally, results indicated Extrinsic Motivation: Avoid Failure was positively related to Extrinsic Motivation: Approach Success, but negatively correlated with respondents' age. Weekly practice hours were negatively correlated with Extrinsic Motivation: Avoid Failure, but positively correlated with Intrinsic Motivation: Growth.

Findings from the qualitative and quantitative studies indicated that undergraduate and graduate instrumentalists felt intrinsically motivated to practice and make progress on their instruments. However, graduate instrumentalists reported that they were also extrinsically motivated to practice for reasons such as preparing for lessons and future careers and were negatively influenced by external challenges (e.g., changing social contexts, pressure from assignments). Moreover, undergraduate instrumentalists used analytic strategies and organized practice sessions less frequently, whereas graduate instrumentalists more frequently used self-regulation skills while practicing, including flexibly planning and setting goals and monitoring progress. 


\section{Suggestions for Studio Instructors}

Collegiate instrumentalist respondents in the survey study (Chapter 4) reported that they practiced less than they intended and seldom analyzed or organized practice tasks. According to these findings, instructors should consider teaching and modeling metacognitive and self-regulation skills during studio lessons. For example, demonstrating a process about how to use various practice skills to accomplish a difficult section, monitoring practice progress, and designing plans to solidify progress based on individual needs. Besides learning practice strategies from instructors, collegiate instrumentalists were also inclined to learn from their peers $(68 \%)$ and through selfexploration (70.3\%) such as reading research articles and participating in workshops. Instructors should consider organizing studio seminars to encourage students to share their performance skills and experiences and construct a collaborative learning context. Additionally, music education faculty and studio instructors could work together to provide regular workshops and conduct research related about instrumental learning and performance to facilitate students' expertise development. As a result, creating opportunities to develop and enrich practice strategies and self-regulation skills might help improve instrumentalists' performance achievement (Bonneville-Roussy \& Bouffard, 2015).

Results indicated that graduate instrumentalists were both intrinsically and extrinsically motivated to practice. Although music practice is expected to be driven by intrinsic motivation, which positively correlates with time devoted to practice and performance achievement (Schatt, 2011; Schmidt, 2005), professional musicians have indicated that they "practiced only in preparation for specific engagements, [and] students 
can also be motivated by this way" (Hallam, 2002, p. 17). Considering that intrinsic and extrinsic motivation "should not be interpreted as mutually exclusive or dichotomous categories because human behavior is often complex and multiply determined" (MacIntyre et al., 2017, p. 700), it is possible that when graduate instrumentalists were motivated to practice due to preparing for lessons, they performed a varied repertoire and explored music that interested them, a process that may have contributed to their intrinsic motivation. Perhaps studio instructors should consider assigning repertoire with different musical forms and styles each semester or providing multiple choices of repertoire, which would allow students to practice pieces that interest them. Moreover, because competitiveness (e.g., future auditions, doctoral program applications) motivated graduate instrumentalists to practice, studio instructors should provide individualized instructions to help students prepare for their future careers.

External challenges negatively influenced participants' practice efficiency. To cope with the pressure from course assignments, music instructors should consider assigning homework that combines theoretical knowledge with practical applications. For example, music history instructors may consider encouraging students to incorporate theoretical knowledge and their primary instruments when completing assignments, such as introducing how musical styles reflected the society of the time and to what extent that instrumental performance skills or musical forms were influenced. This connection may inspire students to explore historical knowledge related to their primary instrument, improve musicianship, and arouse students' internal learning interests. Additionally, collegiate instrumentalists reported that they temporarily left campus and had to keep learning with limited resources during Covid-19. Given these findings, instrumental 
instructors and collegiate musicians should work together to discuss challenges they encountered and potential solutions that could adapt to learning contexts during the pandemic or other emergencies. Studio lessons may also involve other instructions such as theoretical knowledge and career development so that instrumentalists can avoid feeling disconnected with their instruments and studio instructors when coming back on campus. Teaching with flexibility and diversity during events such as Covid-19 should be taken into account by instrumental instructors, as this would ensure that collegiate instrumentalists continue their development.

\section{Discussion}

The investigations in this dissertation were conducted to better understand collegiate instrumentalists' practice habits and motivation orientations. Collegiate instrumentalists, including undergraduate and graduate musicians, reported that their actual weekly practice time was less than their intended practice time (Chapter 4). Graduate instrumentalists spent more hours in weekly practice than undergraduate instrumentalists (Chapter 4). Results of previous studies indicated that musicians with higher levels of expertise spent more time practicing than musicians with lower levels of expertise (Byo \& Cassidy, 2008) because advanced musicians are more likely to practice pieces involving complicated technical skills and participate in multiple musical activities compared to novices (Hallam et al., 2012). Collegiate instrumentalists most frequently used systematic strategies, followed by correction of errors, metronome and recordings, concentration, analytic strategies, and organization (Chapter 4). This result may be due to participants' limited self-regulation skills (i.e., time management, planning and setting goals, self-evaluation abilities), a finding consistent with those involving collegiate 
instrumentalists who did not organize their practice efficiently (Kostka, 2002). Graduate instrumentalists' practice was mostly intrinsically motivated, but also involved extrinsic motivation (Chapter 3). Although investigators have found that intrinsic motivation was positively related to musicians' time spent in practice and commitment to instrumental learning (Diaz, 2010; Schatt, 2011; Schmidt, 2005), Hallam (1995) indicated that advanced musicians exhibited both intrinsic and extrinsic motivation toward practice. Examining ways that extrinsic motivation affects collegiate instrumentalists' practice could help guide studio instructors and ensemble directors' course design efforts.

The frequency with which participants applied practice strategies as reported in Chapter 4 was related to their self-regulation skills. Respondents in the survey study were mainly undergraduate instrumentalists $(n=100,78.1 \%)$ who reported that they less frequently used analytic strategies and organized practice sessions and had a shorter attention span than did graduate instrumentalists, who flexibly planned practice based on individual schedules, applied analytic strategies to solve problems, and arranged their practice time (Chapter 3). Taken together, the findings of these two studies seem to indicate that instrumentalists' self-regulation skills are associated with the development of performance skills. This result is consistent with the finding that younger musicians were more likely to rely on external resources (i.e., teachers, environments) in their practice processes than experienced musicians (Araújo, 2016). Specifically, advanced and professional musicians applied metacognitive skills, such as monitoring and evaluating practice progress and revising practice plans toward specific performance goals, to improve their practice efficiency (Araújo, 2016; Concina, 2019; Nielsen, 2001). Because researchers found that self-regulation skills were related to musicians' practice strategy 
applications (Miksza et al., 2012), focused attention and performance achievement (Bonneville-Roussy \& Bouffard, 2015), and daily practice time (Araújo, 2016), it seems important to examine their interactive effects, which would facilitate our understanding of the interrelations between them. Moreover, results would help instructors identify specific performance skills or potential factors that may affect the development of collegiate musicians' self-regulation skills and further inform their teaching practices.

Results indicated that external challenges could hinder graduate instrumentalists' motivation to practice. Due to the impact of Covid-19, music teachers and their students encountered unprecedented challenges such as accessing instruments and planning instruction through remote learning (Hash, 2021). Likewise, participants in the current study (Chapter 3) discussed the challenges they faced including shortened practice time and losing the opportunity to practice instruments for months due to limited practice room availability. Although the purpose of this investigation was not to focus on the impact of Covid-19, findings such as reduced practice time and negative psychological state were identified. In the future, researchers should consider examining impacts of Covid-19 or other unexpected events (e.g., natural disasters) on collegiate instrumentalists' practice and studio instructors' teaching, which would provide specific information about the process and approaches to cope with these challenges.

\section{Conclusion}

Practice is critical to musicians' expertise development. I designed this dissertation to better understand collegiate instrumentalists' practice habits and motivation. The findings of this dissertation provided specific information to guide instrumental instructors' teaching practices especially in technical skills and practice 
organization. Therefore, instructors may consider enriching their students' practice strategies to improve practice efficiency. Further investigations could add other variables, such as self-regulation behaviors, performance achievement, and deliberate practice strategies, to develop a model that can provide specific or alternative explanations about how these factors relate to each other and potentially affect collegiate instrumentalists' performance achievement. Results may facilitate our understanding of musicians' expertise development and instrumental instructors' teaching effectiveness. As such, musicians could learn how to organize more productive practice sessions and achieve strong and independent musicianship, which may contribute to musicians' performance achievement and the quality of their life and happiness. 


\section{References}

Adedoyin, O. B., \& Soykan, E. (2020). Covid-19 pandemic and online learning: the challenges and opportunities. Interactive Learning Environments, 1-13. https://doi.org/10.1080/10494820.2020.1813180

Araújo, M. V. (2016). Measuring self-regulated practice behaviours in highly skilled musicians. Psychology of Music, 44(2), 278-292. https://doi.org/10.1177/0305735614567554

Asmus, E. P. (1994). Motivation in music teaching and learning. The Quarterly Journal of Music Teaching and Learning, 5(4), 5-32. http://wwwusr.rider.edu/ vrme/v16n1/volume5/visions/winter2.pdf

Austin, J. R., \& Berg, M. H. (2006). Exploring music practice among sixth-grade band and orchestra students. Psychology of Music, 34(4), 535-558. https://doi.org/10.1177/0305735606067170

Bailey, L. W. (2006). A study of motivation and self-regulation among high school instrumental music students [Doctoral dissertation, Capella University].

Bandura, A. (1997). Self-efficacy: The exercise of control. New York: Freeman.

Bangs, R. L. (1992). An application of Amabile's model of creativity to music instruction: A comparison of motivational strategies [Doctoral dissertation, University of Miami].

Barry, N. H. (1992). The effects of practice strategies, individual differences in cognitive style, and gender upon technical accuracy and musicality of student instrumental performance. Psychology of Music, 20(2), 112-123.

https://doi.org/10.1177/0305735692202002 
Barry, N. H. (2007). A qualitative study of applied music lessons and subsequent student practice sessions. Contributions to Music Education, 34, 51-65. https://www.jstor.org/stable/24127258

Barry, N. H., \& Hallam, S. (2002). Practice. In R. Parncutt \& G. McPherson (Eds.), The science and psychology of music performance: Creative strategies for teaching and learning (pp. 151-166). Oxford University Press.

Berger, R. (2015). Now I see it, now I don't: Researcher's position and reflexivity in qualitative research. Qualitative Research, 15(2), 219-234. https://doi.org/10.1177/1468794112468475

Birt, L., Scott, S., Cavers, D., Campbell, C., \& Walter, F. (2016). Member checking: A tool to enhance trustworthiness or merely a nod to validation? Qualitative Health Research, 26(13), 1802-1811. https://doi.org/10.1177/1049732316654870

Bolkan, S., Goodboy, A. K., \& Griffin, D. J. (2011). Teacher leadership and intellectual stimulation: Improving students' approaches to studying through intrinsic motivation. Communication Research Reports, 28(4), 337-346.

Bonneville-Roussy, A., \& Bouffard, T. (2015). When quantity is not enough:

Disentangling the roles of practice time, self-regulation and deliberate practice in musical achievement. Psychology of Music, 43(5), 686-704. https://doi.org/10.1177/0305735614534910

Bonneville-Roussy, A., Lavigne, G. L., \& Vallerand, R. J. (2011). When passion leads to excellence: The case of musicians. Psychology of Music, 39(1), 123-138. https://doi.org/10.1177/0305735609352441 
Braun, V., \& Clarke, V. (2006). Using thematic analysis in psychology. Qualitative Research in Psychology, 3(2), 77-101. https://doi.org/10.1191/1478088706qp063oa

Byo, J. L., \& Cassidy, J. W. (2008). An exploratory study of time use in the practice of music majors: Self-report and observation analysis. Update: Applications of Research in Music Education, 27(1), 33-40. https://doi.org/10.1177/8755123308322272

Cahn, D. (2008). The effects of varying ratios of physical and mental practice, and task difficulty on performance of a tonal pattern. Psychology of Music, 36(2), 179-191. https://doi.org/10.1177/0305735607085011

Campitelli, G., \& Gobet, F. (2011). Deliberate practice: Necessary but not sufficient. Current Directions in Psychological Science, 20(5), 280-285. https://doi.org/10.1177/0963721411421922

Chaffin, R., \& Imreh, G. (2001). A Comparison of Practice and Self-Report as Sources of Information About the Goals of Expert Practice. Psychology of Music, 29(1), 3969. https://doi.org/10.1177/0305735601291004

Charmaz, K. (2014). Constructing grounded theory. Sage Publications.

Chase, W. G., \& Simon, H. A. (1973). The mind's eye in chess. In W. G. Chase (Ed.), Visual information processing. Academic Press.

Christensen, S. E. (2010). Practicing strategically: The difference between knowledge and action in two eighth-grade students' independent instrumental practice. Update: Applications of Research in Music Education, 29(1), 22-32. https://doi.org/10.1177/8755123310377924 
Concina, E. (2019). The role of metacognitive skills in music learning and performing: Theoretical features and educational implications. Frontiers in Psychology, 10, 1583. https://doi.org/10.3389/fpsyg.2019.01583

Connolly, C., \& Williamon, A. (2004). Mental skills training. In A. Williamon (Ed.), Musical Excellence: Strategies and Techniques to Enhance Performance. Oxford University Press.

Creech, A. (2010). Learning a musical instrument: The case for parental support. Music Education Research, 12(1), 13-32. https://doi.org/10.1080/14613800903569237

Cremaschi, A. M. (2012). The effect of a practice checklist on practice strategies, practice self-regulation and achievement of collegiate music majors enrolled in a beginning class piano course. Research Studies in Music Education, 34(2), 223-

\section{3. https://doi.org/10.1177/1321103X12464743}

Creswell, J. W., \& Poth, C. N. (2016). Qualitative inquiry and research design: Choosing among five approaches. Sage publications.

Daumiller, M., Rinas, R., Hein, J., Janke, S., Dickhäuser, O., \& Dresel, M. (2021). Shifting from face-to-face to online teaching during COVID-19: The role of university faculty achievement goals for attitudes towards this sudden change, and their relevance for burnout/engagement and student evaluations of teaching quality. Computers in Human Behavior, 118. https://doi.org/https://doi.org/10.1016/j.chb.2020.106677

Davidson, J. W., Sloboda, J. A., \& Howe, M. J. A. (1995). The role of parents and teachers in the success and failure of instrumental learners. Bulletin of the Council 
for Research in Music Education, 127, 40-44.

https://www.jstor.org/stable/40318764

Denzin, N. K., \& Lincoln, Y. S. (2011). The Sage handbook of qualitative research (4th ed.). Sage Publications.

Diaz, F. M. (2010). Intrinsic and extrinsic motivation among collegiate instrumentalists. Contributions to Music Education, 37, 23-35.

Donald, L. S. (1997). The organization of rehearsal tempos and efficiency of motor skill acquisition in piano performance [Doctoral dissertation, The University of Texas at Austin].

https://search.proquest.com/pqdt/docview/304372937/abstract/4003D1C282734C $\underline{\mathrm{E} 6 \mathrm{PQ} / 1}$

Downing, K., Kwong, T., Chan, S.-W., Lam, T.-F., \& Downing, W.-K. (2009). Problembased learning and the development of metacognition. Higher Education, 57(5), 609-621. https://doi.org/10.1007/s10734-008-9165-x

Driscoll, J. (2009). 'If I play my sax my parents are nice to me': opportunity and motivation in musical instrument and singing tuition. Music Education Research, 11(1), 37-55. https://doi.org/10.1080/14613800802547722

Duke, R. A., Simmons, A. L., \& Cash, C. D. (2009). It's not how much; It's how: Characteristics of practice behavior and retention of performance skills. Journal of Research in Music Education, 56(4), 310-321. https://doi.org/10.1177/0022429408328851

Dweck, C. S. (1986). Motivational processes affecting learning. American psychologist, 41(10), 1040. 
Elliot, A. J. (2005). A conceptual history of the achievement goal construct. In A. J. Elliot \& C. S. Dweck (Eds.), Handbook of competence and motivation (pp. 52-72). NY: Guilford Press.

Elliot, A. J., \& McGregor, H. A. (2001). A $2 \times 2$ achievement goal framework. Journal of Personality and Social Psychology, 80(3), 501-519. https://doi.org/10.1037/0022-3514.80.3.501

Ericsson, K. A. (1996). The road to excellence: The acquisition of expert performance in the arts and sciences, sports, and games. Lawrence Erlbaum Associates.

Ericsson, K. A., Krampe, R. T., \& Tesch-Römer, C. (1993). The role of deliberate practice in the acquisition of expert performance. Psychological Review, 100(3), 363-406. https://doi.org/10.1037/0033-295X.100.3.363

Fine, P. A., Wise, K. J., Goldemberg, R., \& Bravo, A. (2015). Performing musicians' understanding of the terms "mental practice" and "score analysis". Psychomusicology: Music, Mind, and Brain, 25(1), 69-82. $\underline{\text { https://doi.org/10.1037/pmu0000068 }}$

Fung, A. S. K. (2018). Confucian heritage culture, parental differential treatment of siblings and music learning: A hermeneutic analysis of a musical family. Psychology of Music, 46(3), 357-374. https://doi.org/10.1177/0305735617712423

Gabrielsson, A. (1999). The performance of music. In D. Deutsch (Ed.), The psychology of music (2nd ed., pp. 501-602). San Diego: Academic Press.

Gardner, L. (2020). What higher ed has learned from Covid-19 so far. The Chronicle of Higher Education, 67(6). https://www.chronicle.com/article/what-higher-ed-haslearned-from-covid-19-so-far 
George, D., \& Mallery, P. (2002). SPSS for Windows step by step: A simple study guide and reference, 11.0 update (4th ed.). Boston: Allyn \& Bacon.

Geringer, J. M., Macleod, R. B., \& Lofdahl, H. (2015). A survey of practice behaviors among middle and high school string players. String Research Journal, 6(1), 5569. https://doi.org/10.1177/194849921500600004

Graaff, D. (2014). Practice strategies of an elite instrumental performer: A case study under test conditions, comparing quantitative data to coded Think Aloud and interview [Doctoral dissertation, University of New South Wales].

Gruson, L. M. (1988). Rehearsal skill and musical competence: Does practice make perfect? In J. Sloboda (Ed.), Generative processes in music: The psychology of performance, improvisation, and composition (pp. 91-112). Clarendon Press.

Hallam, S. (1995). Professional musicians' orientations to practice: Implications for teaching. British Journal of Music Education, 12(1), 3-19.

Hallam, S. (1997). Approaches to instrumental music practice of experts and novices: Implications for education. In H. Jørgensen \& A. C. Lehmann (Eds.), Does practice make perfect?: Current theory and research on instrumental music practice (pp. 179-231). Norges musikkhøgskole.

Hallam, S. (1998). The predictors of achievement and dropout in instrumental tuition. Psychology of Music, 26(2), 116-132. https://doi.org/10.1177/0305735698262002

Hallam, S. (2001a). The development of expertise in young musicians: Strategy use, knowledge acquisition and individual diversity. Music Education Research, 3(1), 7-23. https://doi.org/10.1080/14613800020029914 
Hallam, S. (2001b). The development of metacognition in musicians: Implications for education. British Journal of Music Education, 18(1), 27-39. https://doi.org/10.1017/S0265051701000122

Hallam, S. (2002). Musical motivation: Towards a model synthesising the research. Music Education Research, 4(2), 225-244. https://discovery.ucl.ac.uk/id/eprint/10002218/

Hallam, S., Creech, A., Varvarigou, M., \& Papageorgi, I. (2020). Are there differences in practice depending on the instrument played? Psychology of Music, 48(6), 745765. https://doi.org/10.1177/0305735618816370

Hallam, S., Rinta, T., Varvarigou, M., Creech, A., Papageorgi, I., Gomes, T., \& Lanipekun, J. (2012). The development of practising strategies in young people. Psychology of Music, 40(5), 652-680. https://doi.org/10.1177/0305735612443868

Hamlin, P. (2014). Deliberate practice of high school instrumentalists: A theoretical model [Doctoral dissertation, University of Miami]. https://scholarship.miami.edu/discovery/fulldisplay/alma991031447516402976/0 1UOML INST:ResearchRepository

Harnum, J. (2013). The practice of practice: A collective case study of how music practice is conceived, executed, and learned by professional musicians in four genres of music [Doctoral dissertation, Northwestern University]. https://search.proquest.com/pqdt/docview/1446721909/105C05617E454EA8PQ/1 ?accountid=14576 
Hash, P. M. (2021). Remote learning in school bands during the COVID-19 shutdown. Journal of Research in Music Education, 68(4), 381-397. https://doi.org/10.1177/0022429420967008

Hickok, S. C. (2009). The relationships of parental involvement, motivating factors, and socioeconomic status to high school all-state choir and band membership [Doctoral dissertation, Auburn University]. https://search.proquest.com/pqdt/docview/304829669/abstract/9E15B120CA1048 77PQ/7

Ho, W. (2011). Parental support and student learning of musical instruments in Hong Kong. Visions of Research in Music Education, 19, 1-53.

Horrocks, D. E., McKenna, J., Whitehead, A. E., Taylor, P. J., Morley, A. M., \& Lawrence, I. (2016). Preparation, structured deliberate practice and decision making in elite level football: The case study of Gary Neville (Manchester United FC and England). International Journal of Sports Science \& Coaching, 11(5), 673-682. https://doi.org/10.1177/1747954116667105

Horsley, P. T. (2019). Instrumental music teacher perceptions regarding student selfregulation of music learning [Doctoral dissertation, University of MissouriColumbia]. https://mospace.umsystem.edu/xmlui/handle/10355/70070

Hruska, B. J. (2011). Using mastery goals in music to increase student motivation. Update: Applications of Research in Music Education, 30(1), 3-9. https://doi.org/10.1177/8755123311418477 
Johnson, E. (2015). Peer-teaching in the secondary music ensemble. Journal of Education and Training Studies, 3(5), 35-42. https://doi.org/10.11114/jets.v3i5.906

Jørgensen, H. (1996). Tid til фving? Studentenes bruk av tid til фving ved Norges musikkhøgskole [Time for practising? Students' use of time for practising at the Norwegian academy of music]. Norges Musikkhogskole.

Jørgensen, H. (1998). Planlegges фving? (Is practice planned?). Oslo: Norwegian State Academy of Music.

Jørgensen, H. (2002). Instrumental performance expertise and amount of practice among instrumental students in a conservatoire. Music Education Research, 4(1), 105119. https://doi.org/10.1080/14613800220119804

Jørgensen, H. (2004). Strategies for individual practice. In A. Williamon (Ed.), Musical excellence: Strategies and techniques to enhance performance (pp. 85-103). Oxford University Press.

Kim, H., Sefcik, J. S., \& Bradway, C. (2017). Characteristics of qualitative descriptive studies: A systematic review. Research in Nursing \& Health, 40(1), 23-42. https://doi.org/10.1002/nur.21768

Kostka, M. J. (2002). Practice expectations and attitudes: A survey of college-level music teachers and students. Journal of Research in Music Education, 50(2), 145-154. https://doi.org/10.2307/3345818

Kremer, J., Moran, A., Walker, G., \& Craig, C. (2012). Achievement goal theory. In Key Concepts in Sport Psychology. Sage Publications. 
http://knowledge.sagepub.com/view/key-concepts-in-sport-

psychology/SAGE.xml

Krogius, N. V. (1976). Psychology in chess. R.H.M. Press.

Lacaille, N., Koestner, R., \& Gaudreau, P. (2016). On the value of intrinsic rather than traditional achievement goals for performing artists: A short-term prospective study. International Journal of Music Education, 25(3), 245-257. https://doi.org/10.1177/0255761407083578

Lehmann, A. C. (1997). Acquired mental representations in music performance: Anecdotal and preliminary empirical evidence. In H. Jørgensen \& A. C. Lehmann (Eds.), Does practice make perfect?: Current theory and research on instrumental music practice (pp. 141-164). Norges musikkhøgskole.

Leon-Guerrero, A. J. (2004). An examination of the self-regulation strategies used by adolescent instrumental musicians while practicing [Doctoral dissertation, Northwestern University].

https://search.proquest.com/pqdt/docview/305136241/abstract/C232FC31A33D40

\section{$\underline{\mathrm{D} 5 \mathrm{PQ} / 1}$}

Lim, S., \& Lippman, L. G. (1991). Mental practice and memorization of piano music. The Journal of General Psychology, 118(1), 21-30.

Liu, C. (2009). Relationships between siblings engaged in music study: An exploratory investigation [Doctoral dissertation, University of Missouri-Columbia]. https://mospace.umsystem.edu/xmlui/handle/10355/6766

Liu, C., \& Sims, W. (2008). Sibling relationships on music learning. National Music Educators Association 61st Annual Conference, Wisconsin, the United States. 
Liu, Y. (2021). Differences in practice time and strategies among Chinese music majors [Unpublished manuscript].

MacIntyre, P. D., Schnare, B., \& Ross, J. (2017). Self-determination theory and motivation for music. Psychology of Music, 46(5), 699-715. https://doi.org/10.1177/0305735617721637

Macnamara, B. N., Hambrick, D. Z., \& Oswald, F. L. (2014). Deliberate practice and performance in music, games, sports, education, and professions: A metaanalysis. Psychological Science, 25(8), 1608-1618. https://doi.org/10.1177/0956797614535810

Mawang, L. L., Kigen, E. M., \& Mutweleli, S. M. (2020). Achievement goal motivation and cognitive strategies as predictors of musical creativity among secondary school music students. Psychology of Music, 48(3), 421-433. https://doi.org/10.1177/0305735618805837

McCormick, J., \& McPherson, G. (2003). The role of self-efficacy in a musical performance examination: An exploratory structural equation analysis. Psychology of Music, 31(1), 37-51. https://doi.org/10.1177/0305735603031001322

McPherson, G., \& Davidson, J. (2002). Musical practice: Mother and child interactions during the first year of learning an instrument. Music Education Research, 4(1), 141-156. https://doi.org/10.1080/14613800220119822

McPherson, G., \& Renwick, J. (2001). A longitudinal study of self-regulation in children's musical practice. Music Education Research, 3(2), 169-186. https://doi.org/10.1080/14613800120089232 
McPherson, G. E. (2005). From child to musician: Skill development during the beginning stages of learning an instrument. Psychology of Music, 33(1), 5-35.

McPherson, G. E., \& McCormick, J. (2000). The contribution of motivational factors to instrumental performance in a music examination. Research Studies in Music Education, 15(1), 31-39. https://doi.org/10.1177/1321103X0001500105

McPherson, G. E., \& McCormick, J. (2006). Self-efficacy and music performance. Psychology of Music, 34(3), 322-336. https://doi.org/10.1177/0305735606064841

McPherson, G. E., \& Zimmerman, B. J. (2002). Self-regulation of musical learning: A social cognitive perspective. In R. Colwell \& C. Richardson (Eds.), The new handbook of research on music teaching and learning: a project of the Music Educators National Conference (pp. 327-347). Oxford University Press.

McPherson, G. E., \& Zimmerman, B. J. (2011). Self-regulation of musical learning: A social cognitive perspective on developing performance skills. In R. Colwell \& P. Webster (Eds.), MENC handbook of research on music learning (Vol. 2, pp. 130175). Oxford University Press.

Miklaszewski, K. (1989). A Case Study of a Pianist Preparing a Musical Performance. Psychology of Music, 17(2), 95-109. https://doi.org/10.1177/0305735689172001

Miksza, P. (2006a). An exploratory investigation of self-regulatory and motivational variables in the music practice of junior high band students. Contributions to Music Education, 33(2), 9-26. https://www.jstor.org/stable/24127206

Miksza, P. (2006b). Relationships among impulsiveness, locus of control, sex, and music practice. Journal of Research in Music Education, 54(4), 308-323. https://doi.org/10.1177/002242940605400404 
Miksza, P. (2007). Effective practice: An investigation of observed practice behaviors, self-reported practice habits, and the performance achievement of high school wind players. Journal of Research in Music Education, 55(4), 359-375. https://doi.org/10.1177/0022429408317513

Miksza, P. (2009). Relationships among impulsivity, achievement goal motivation, and the music practice of high school wind players. Bulletin of the Council for Research in Music Education, 180, 9-27. https://www.jstor.org/stable/40319317

Miksza, P. (2010). Relationships among achievement goal motivation, impulsivity, and the music practice of collegiate brass and woodwind players. Psychology of Music, 39(1), 50-67. https://doi.org/10.1177/0305735610361996

Miksza, P. (2015). The effect of self-regulation instruction on the performance achievement, musical self-efficacy, and practicing of advanced wind players. Psychology of Music, 43(2), 219-243. https://doi.org/10.1177/0305735613500832

Miksza, P., Prichard, S., \& Sorbo, D. (2012). An observational study of intermediate band students' self-regulated practice behaviors. Journal of Research in Music Education, 60(3), 254-266. https://doi.org/10.1177/0022429412455201

Miksza, P., \& Tan, L. (2015). Predicting collegiate wind players' practice efficiency, flow, and self-efficacy for self-regulation: An exploratory study of relationships between teachers' instruction and students' practicing. Journal of Research in Music Education, 63(2), 162-179. https://doi.org/10.1177/0022429415583474

Moder, J. A. (2013). Factors influencing non-music majors' decisions to participate in collegiate bands [Doctoral dissertation, University of Missouri - Kansas City]. 
Nicholls, J. G. (1989). The competitive ethos and democratic education. Harvard University Press.

Nielsen, S. G. (1997). Self-regulation of learning strategies during practice: A case study of a church organ student preparing a musical work for performance. In $\mathrm{H}$. Jørgensen \& A. C. Lehmann (Eds.), Does Practice Make Perfect? Current Theory and Research on Instrumental Music Practice (pp. 109-122). Norges musikkhøgskole.

Nielsen, S. G. (1999). Learning strategies in instrumental music practice. British Journal of Music Education, 16(3), 275-291.

Nielsen, S. G. (2001). Self-regulating learning strategies in instrumental music practice. Music Education Research, 3(2), 155-167. https://doi.org/10.1080/14613800120089223

Nielsen, S. G. (2004). Strategies and self-efficacy beliefs in instrumental and vocal individual practice: A study of students in higher music education. Psychology of Music, 32(4), 418-431. https://doi.org/10.1177/0305735604046099

Nielsen, S. G. (2008). Achievement goals, learning strategies and instrumental performance. Music Education Research, 10(2), 235-247. https://doi.org/10.1080/14613800802079106

Norgaard, M. (2008). Descriptions of improvisational thinking by artist-level jazz musicians [Doctoral Dissertation, The University of Texas at Austin].

O’Neill, S. (1997). The role of practice in children's early performance achievement. In H. Jørgensen \& A. C. Lehmann (Eds.), Does practice make perfect?: Current 
theory and research on instrumental music practice (pp. 52-70). Norges musikkhøgskole.

Pajares, F. (2003). Self-efficacy beliefs, motivation, and achievement in writing: A review of the literature. Reading and Writing Quarterly, 19(2), 139-158. https://doi.org/10.1080/10573560308222

Patel, V. L., Kaufman, D. R., \& Magder, S. A. (1996). The acquisition of medical expertise in complex dynamic environments. In H. Jørgensen (Ed.), The road to excellence: The acquisition of expert performance in the arts and sciences, sports, and games (pp. 127-165). Lawrence Erlbaum Associates, Inc.

Patton, M. (2002). Qualitative Research and Evaluation Methods (3rd ed.). Sage Publications.

Perez, R. A. (2011). Middle school instrumental music students' perceptions of their practice habits and influences [Master's thesis, University of Southern California].

Petersen, E. A. (2018). Find what works best for you: Learning to practice in a large ensemble [Doctoral dissertation, Ohio State University]. https://etd.ohiolink.edu/pg_10?::NO:10:P10_ETD_SUBID:174402

Pike, P. D. (2017). Self-regulation of teenaged pianists during at-home practice. Psychology of Music, 45(5), 739-751. https://doi.org/10.1177/0305735617690245

Pintrich, P. R., Smith, D. A., Garcia, T., \& McKeachie, W. J. (1991). A manual for the use of the Motivated Strategies for Learning Questionnaire (MSLQ). Technical Report No. 91-b-004, Michigan: University of Michigan. 
Pitts, S., \& Davidson, J. (2000). Developing effective practise strategies: Case studies of three young instrumentalists. Music Education Research, 2(1), 45-56. https://doi.org/10.1080/14613800050004422

Prichard, S. (2017). Music practice instruction in middle school instrumental ensembles: An exploratory analysis. Bulletin of the Council for Research in Music Education, 213, 73-86. https://doi.org/10.5406/bulcouresmusedu.213.0073

Prichard, S. (2020). The impact of music practice instruction on middle school band students' independent practice behaviors. Journal of Research in Music Education. https://doi.org/10.1177/0022429420947132 (Advance online publication)

Rohwer, D., \& Polk, J. (2006). Practice behaviors of eighth-grade instrumental musicians. Journal of Research in Music Education, 54(4), 350-362. https://doi.org/10.1177/002242940605400407

Rosenthal, R. K., Wilson, M., Evans, M., \& Greenwalt, L. (1988). Effects of different practice conditions on advanced instrumentalists' performance accuracy. Journal of Research in Music Education, 36(4), 250-257. https://doi.org/10.2307/3344877

Rubin, H. J., \& Rubin, I. S. (2011). Qualitative interviewing: The art of hearing data. Sage Publications.

Ryan, R. M., \& Deci, E. L. (2000). Intrinsic and extrinsic motivations: Classic definitions and new directions. Contemporary Educational Psychology, 25(1), 54-67. https://doi.org/10.1006/ceps.1999.1020 
Sandelowski, M. (2000). Whatever happened to qualitative description? Research in Nursing \& Health, 23(4), 334-340. https://doi.org/10.1002/1098240X(200008)23:4<334::AID-NUR9>3.0.CO;2-G

Sandene, B. A. (1997). An investigation of variables related to student motivation in instrumental music [Doctoral dissertation, University of Michigan].

Schatt, M. D. (2011). High school instrumental music students' attitudes and beliefs regarding practice: An application of attribution theory. Update: Applications of Research in Music Education, 29(2), 29-40. https://doi.org/10.1177/8755123310396981

Schmidt, C. P. (2005). Relations among motivation, performance achievement, and music experience variables in secondary instrumental music students. Journal of Research in Music Education, 53(2), 134-147. https://doi.org/10.2307/3345514

Simmons, A. L., Allen, S. E., Hamilton, L. M., Cash, C. D., \& Duke, R. A. (2021, January). "Make it better": Developing musicians' plans for practice [Poster presentation]. Missouri Music Educators Associate State Conference, Missouri, the United States. https://mmea.net/wp-content/uploads/2021/01/15-SimmonsMMEA-2021-1.pdf

Sloboda, J. A., \& Davidson, J. (1996). The young performing musician. In I. Deliège \& J. Sloboda (Eds.), Musical beginnings: Origins and development of musical competence. Oxford University Press. https://www.oxfordscholarship.com/view/10.1093/acprof:oso/9780198523321.00 $\underline{1.0001 / a c p r o f-9780198523321}$ 
Sloboda, J. A., Davidson, J. W., Howe, M. J. A., \& Moore, D. G. (1996). The role of practice in the development of performing musicians. British Journal of Psychology, 87(2), 287-309. https://doi.org/10.1111/j.2044-8295.1996.tb02591.x

Smith, J. (2020, March). Avoiding communication fatigue as coronavirus separates workforce. Public Relations Society of America. https://prsay.prsa.org/2020/03/20/avoiding-communication-fatigue-ascoronavirus-separates-workforces/

Tan, L., \& Miksza, P. (2019). Motivational orientations of college band students: A cross-cultural examination of a collective 2 x 2 achievement goal model. Psychology of Music, 47(1), 33-50. https://doi.org/10.1177/0305735617734628

Upitis, R., Abrami, P. C., Brook, J., \& King, M. (2017). Parental involvement in children's independent music lessons. Music Education Research, 19(1), 74-98. https://doi.org/10.1080/14613808.2016.1202220

Wang, C. K. J., Tan, L., \& Dairianathan, E. I. (2018). Achievement goals, implicit theories, and intrinsic motivation: A test of domain specificity across music, visual art, and sports. Journal of Research in Music Education, 66(3), 320-337. https://doi.org/10.1177/0022429418784563

Wang, X., Hegde, S., Son, C., Keller, B., Smith, A., \& Sasangohar, F. (2020). Investigating mental health of US college students during the COVID-19 pandemic: Cross-sectional survey study. Journal of Medical Internet Research, 22(9). https://doi.org/10.2196/22817 
Webb, R. S. (2015). An exploration of three peer tutoring cases in the school orchestra program. Bulletin of the Council for Research in Music Education, 203, 63-80. https://doi.org/10.5406/bulcouresmusedu.203.0063

Yin, R. K. (2009). Case study research: Design and methods (4th ed.). Sage Publications.

Yoo, H. (2020). A motivational sequence model of high school ensemble students' intentions to continue participating in music. Journal of Research in Music Education. https://doi.org/10.1177/0022429420954880 (Advance online publication)

Zahneis, M., \& June, A. (2020). How has the pandemic affected graduate students? This study has answers. The Chronicle of Higher Education, 67(2). https://www.chronicle.com/article/how-has-the-pandemic-affected-graduatestudents-this-study-has-answers

Zdzinski, S. F. (1996). Parental involvement, selected student attributes, and learning outcomes in instrumental music. Journal of Research in Music Education, 44(1), 34-48. https://doi.org/10.2307/3345412

Zelenak, M. S. (2014). Measuring the sources of self-efficacy among secondary school music students. Journal of Research in Music Education, 62(4), 389-404. https://doi.org/10.1177/0022429414555018

Zimmerman, B. J. (1986). Becoming a self-regulated learner: Which are the key subprocesses? Contemporary Educational Psychology, 11(4), 307-313. https://doi.org/10.1016/0361-476X(86)90027-5

Zimmerman, B. J. (2000). Self-efficacy: An essential motive to learn. Contemporary Educational Psychology, 25(1), 82-91. https://doi.org/10.1006/ceps.1999.1016 


\section{Appendix A}

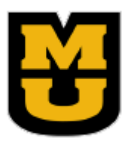

\section{Institutional Review Board}

University of Missouri-Columbia

FWA Number: 00002876

IRB Registration Numbers: 00000731, 00009014
482 McReynolds Hall

Columbia, MO 65211

573-882-3181

irb@missouri.edu

October 19,2020

Principal Investigator: Yue Liu (MU-Student)

Department: Music Education-PHD

Your IRB Application to project entitled Practice Habits and Motivation: A Qualitative Descriptive Study of Advanced Musicians was reviewed and approved by the MU Institutional Review Board according to the terms and conditions described below:

IRB Project Number
IRB Review Number
Initial Application
Approval Date
IRB Expiration Date
Level of Review
Project Status
Exempt Categories
(Revised Common Rule)
Risk Level

Approved Documents
2031622

276864

October 19, 2020

October 19, 2021

Exempt

Active - Exempt

45 CFR 46.104d(2)(ii)

Minimal Risk

I will send the email to potential participants together with the consent form, which includes specific information about the study.

Consent Information

Interview Questions

Questionnaire

The principal investigator (PI) is responsible for all aspects and conduct of this study. The PI must comply with the following conditions of the approval:

\section{COVID-19 Specific Information}

Enrollment and study related procedures must remain in compliance with the University of Missouri regulations related to interaction with human participants following guidance at research.missouri.edu/about/covid-19-info.php

In addition, any restarting of in-person research activities must comply with the policies and guiding principles provided at research.missouri.edu/about/research-restart.php, including appropriate approvals for return to work authorization for individuals as well as human subject research projects.

2. No subjects may be involved in any study procedure prior to the IRB approval date or after the expiration date.

3. All changes must be IRB approved prior to implementation utilizing the Exempt Amendment Form. 
4. The Annual Exempt Form must be submitted to the IRB for review and approval at least 30 days prior to the project expiration date to keep the study active or to close it.

5. Maintain all research records for a period of seven years from the project completion date.

If you are offering subject payments and would like more information about research participant payments, please click here to view the MU Business Policy and Procedure: http://

bppm.missouri.edu/chapter2/2_250.html

If you have any questions or concerns, please contact the MU IRB Office at 573-882-3181 or email to muresearchirb@missouri.edu.

Thank you,

MU Institutional Review Board 


\section{Appendix B}

Email Subject Line: Investigation of Graduate Instrumentalists' Practice Behaviors

\section{Dear XX,}

My name is Yue Liu, and I am currently a doctoral candidate in Music Education under the direction of Dr. Brian Silvey at the University of Missouri-Columbia. I hope that you will consider participating in my dissertation research, which is to examine practice habits and practice motivation among advanced musicians. It will provide insight into the current practices of graduate music performance majors.

In this study, I will ask you to (a) provide a practice video that records a typical practice session, (b) fill out a survey with regard to music practice, (c) describe practice strategies used in your practice recording and its purpose, accompanied by the playing of the video recording, (d) participate in an interview relating to your practice recording, and (e) answer follow-up questions if necessary. The anticipated total time to participate in this project may depend on the length of the practice video.

This research will be used only for educational purposes. Your participation is completely voluntary. All identifying information will be kept confidential. If you are interested in or have any questions about this study, please reply to this email.

Your participation would be greatly appreciated.

Sincerely, Yue Liu 


\title{
Appendix C
}

\section{CONSENT FORM TO PARTICIPATE IN A RESEARCH STUDY}

\section{Practice Habits and Motivation: A Qualitative Descriptive Study of Graduate Instrumentalists}

\author{
Conducted by: Yue Liu \\ School of Music, The University of Missouri \\ Telephone: 573-529-6623 \\ E-mail: yl7nt@umsystem.edu
}

You are being asked to participate in a research study. This form provides you with information about the study. Please read the information below and ask questions about anything you do not understand before deciding whether or not to take part.

You have the right to know what you will be asked to do so that you can decide whether or not to be in the study. Your participation is voluntary. You do not have to be in the study if you do not want to. You may refuse to be in the study and nothing will happen. If you do not want to continue to be in the study, you may stop at any time without penalty or loss of benefits to which you are otherwise entitled. All identifying information will be kept confidential.

The purpose of this study is to examine practice habits and motivation orientations among graduate instrumentalists.

\section{If you agree to participate in the study, I will ask you to do the following things:}

- Provide a practice video that records a typical practice session.

- Fill out a survey with regard to music practice.

- Describe practice strategies used in your practice recording and its purpose, accompanied by the playback of the video recording.

- Participate in a semi-structured interview relating to your practice recording.

- Follow-up questions may be asked if necessary.

The total estimated time to participate in the study varies based on the time length of the practice video recording that is provided by participants.

\section{Risks and Benefits:}

The risk associated with this study is no greater than everyday life. The possible benefits of this study include reflecting on instrumental teaching and learning.

Confidentiality: The recordings and transcriptions used in this study will be stored securely and kept confidential, and only the researcher can access. Pseudonyms will be given for all participants in the qualitative study analysis. 
Contacts and Questions: If you have any questions about the study, please contact me, my contact information is at the top of the page.

You may also contact the University of Missouri - Columbia Institutional Review Board (IRB) if you have questions about your rights as a research participant. The IRB can be reached by phone at 573-882-3181 or email irb@ missouri.edu.

If you want to talk privately about your rights or any issues related to your participation in this study, you can contact University of Missouri Research Participant Advocacy by calling 888-280-5002 (a free call) or emailing MUResearchRPA@ missouri.edu. 


\section{Appendix D \\ Interview Questions}

1. How did you feel about this practice session?

- Were the practice strategies that you used effective? Why or why not?

- Is there anything you might do differently after having watched your video?

2. Does the video represent your typical practice session? If not, what does your practice sessions look like?

3. Do you have a fixed practice routine? If not, what factors may influence your practice routine?

4. What does "practice strategy" mean to you?

5. How and where did you learn practice strategies?

6. What are the major factors that motivate you to practice?

7. What are the reasons that might hinder your practice? 


\section{Appendix E}

\section{Qualitative Study: Data Coding}

I conducted open coding in the qualitative study and narrowed the initial codes into categories and themes to answer research questions.

\section{Theme One: Task-Oriented Practice Routines}

Category one: Giving priority to studio lessons

- Focusing on studio lessons

- Following studio faculty's instructions

- Practicing pieces for lessons

- Giving priority to important tasks

Category two: Flexibly planning and setting goals

- Reducing physical tension

- Depending on individual needs

- Practicing stages (e.g. polishing, learning)

- Aiming to address specific problems

- Preparing for performances and recitals

- Achieving a specific goal

- Having a mental plan

- Explicit goals for a practice session

- Nothing super rigid

- To be successful as a professional musician

Category three: Effectively using practice time

- Deciding to move on at a certain time

- Be productive in practice sessions

- Time management

- Concentration on tasks

- Set aside blocks of time

- Individual practice habits

- Completing other things before practicing

\section{Theme Two: Solution-Oriented Approaches}

Category one: Applying analytic strategies

- Monitoring practice progress

- Identifying differences

- Identifying difficult sections

- Analyzing reasons resulting in the challenges

- Being introspective

- Experimenting with the best way to play

- Playing through to get a sound image and checking errors

- Actively breaking the old habits to build a better way

- Reviewing practice journal to evaluate progress 
Category two: Combining multiple practice strategies to solve a problem

- Slow practice and repetition

- Isolation, repetition, and tempo variation

- Fast and slow practice and then alternating rhythmic patterns

- Isolation, error correction, and repetition

- Repetition and experiment

- Gradually speeding up and repeating isolated sections

- Marking on scores to avoid repeatedly making errors

Category three: Using practice tools

- Avoiding forming bad habits

- Recordings help identify errors

- Breathing tube - a visual tool

- Metronome

- Tuner-intonation check

- Monitoring practice progress

Theme Three: Mixed Motivations

Category one: Enjoying making music

- Accomplishing personal goals

- Enjoying coping with challenges

- Getting better at the instrument

- Making progress

- Loving practicing

- Passion

Category two: Strengthening fundamentals

- Improving technical skills

- Developing expertise

- Scaffold

- Preparing for the future

Category three: Preparing for lessons and performances

- Being competitive

- Job applications

- Rehearsals and auditions

- Doctoral program applications

- Studio lessons

- Getting approval from others because of a good performance

Theme Four: External Challenges

Category one: Changing social contexts (Covid-19)

- Limited practice room availability

- No instruments at home (percussion) - being frustrating

- Mental health

- Shortening practice time

- Practicing at home 
- Disconnection

- Gotten broken practice routine

Category two: Pressure from assignments and jobs

- Being stressed out

- Cutting the length of practice time

- Being hard to focus on practice

- Schoolwork and practice balance

- Answering emails as a TA

Category three: Practice environment

- Rainy weather

- Undesired practice space

- Being tiring

- Being less productive

- Poor practice efficiency

- Negative influences 


\section{Appendix F}

October 19, 2020

Principal Investigator: Yue Liu (MU-Student)

Department: Music Education-PHD

Your IRB Application to project entitled Collegiate Instrumentalists' Applications of Practice Strategies and Practice Motivation was reviewed and approved by the MU Institutional Review Board according to the terms and conditions described below:

IRB Project Number

IRB Review Number

Initial Application Approval Date

IRB Expiration Date

Level of Review

Project Status

Exempt Categories (Revised Common Rule) 45 CFR 46.104d(2)(i)

Risk Level

Approved Documents
2031582

276824

October 19, 2020

October 19, 2021

Exempt

Active - Exempt
Minimal Risk

Recruitment message.

Consent information.

Questionnaire.

The principal investigator (PI) is responsible for all aspects and conduct of this study. The PI must comply with the following conditions of the approval:

\section{COVID-19 Specific Information}

Enrollment and study related procedures must remain in compliance with the University of Missouri regulations related to interaction with human participants following guidance at research.missouri.edu/about/covid-19-info.php

In addition, any restarting of in-person research activities must comply with the policies and guiding principles provided at research.missouri.edu/about/research-restart.php, including appropriate approvals for return to work authorization for individuals as well as human subject research projects.

2. No subjects may be involved in any study procedure prior to the IRB approval date or after the expiration date.

3. All changes must be IRB approved prior to implementation utilizing the Exempt Amendment Form.

4. The Annual Exempt Form must be submitted to the IRB for review and approval at least 30 days prior to the project expiration date to keep the study active or to close it.

5. Maintain all research records for a period of seven years from the project completion date. 
If you are offering subject payments and would like more information about research participant payments, please click here to view the MU Business Policy and Procedure: http://

bppm.missouri.edu/chapter2/2_250.html

If you have any questions or concerns, please contact the MU IRB Office at 573-882-3181 or email to muresearchirb@missouri.edu.

Thank you,

MU Institutional Review Board 


\section{Appendix G}

Email Subject Line: Survey of College Instrumentalists’ Practice Behaviors

\section{Dear Professor XX:}

My name is Yue Liu, and I am currently a doctoral candidate in Music Education under the direction of Dr. Brian Silvey at the University of Missouri-Columbia. I hope that you will consider distributing the following survey link (or this message) to instrumentalists in your ensembles. It will take approximately 10 minutes to complete. The purpose of this study is to examine collegiate instrumentalists' applications of practice strategies and motivation to music practice. It will provide insight into the current practices of collegiate instrumentalists.

This research will be used only for educational purposes. This data will enrich music educators' understanding of how collegiate musicians organize practice sessions and implement practice strategies. Your students' participation would be greatly appreciated.

All records and information collected in this study will be anonymous. Please be assured that I will not disclose any individual's results or identity, or any identifying information in any format.

If you choose to participate in this research project, please copy and paste or forward the following link where your students can access the survey: https://missouri.qualtrics.com/jfe/form/SV_4URiZBP0g66kjzL.

If you have any questions, please feel free to contact me, Yue Liu, at y17nt@umsystem.edu. You may also contact my dissertation advisor, Dr. Brian Silvey, at silveyba@missouri.edu. If you have questions regarding your rights as a participant in research, please contact the University of Missouri Institutional Review Board (IRB) at 573-882-3181.

Sincerely, Yue Liu 


\author{
Appendix H \\ Collegiate Instrumentalists' Applications of Practice Strategies and \\ Practice Motivation \\ Conducted by Yue Liu \\ School of Music, The University of Missouri \\ Telephone: 573-529-6623 \\ E-mail:yl7nt@umsystem.edu
}

You are being asked to participate in a research study. This form provides you with information about the study. Please read the information below and ask questions about anything you do not understand before deciding whether or not to take part. Your participation is entirely voluntary, and you can refuse to participate without penalty or loss of benefits to which you are otherwise entitled. You can stop your participation at any time, and your refusal will not impact current or future relationships with MU or participating sites.

The purpose of this study is to examine collegiate instrumentalists' applications of practice strategies and motivation orientations to music practice.

If you agree to participate in this study, I will ask you to do the following things:

- Provide the frequency with which practice strategies are applied in your practice sessions.

- Rate your level of agreement to items relating to your attitudes and belief in music practice.

- Provide anonymous demographic information.

Total estimated time to participate in the study is 10 minutes.

\title{
Risks and Benefits:
}

The risk associated with this study is no greater than everyday life. Possible benefits of this study include reflecting on individual's practice strategies.

\section{Contacts and Questions:}

If you have any questions about the study, please notify the author. If you have questions later, want additional information, or wish to withdraw your participation, call the researcher conducting the study. The name, phone number, and e-mail address are at the top of this page.

You may contact the University of Missouri Institutional Review Board (IRB) if you have questions about your rights as a research participant. The IRB can be reached at irb@missouri.edu or at 573-882-3181.

If you want to talk privately about your rights or any issues related to your participation in this study, you can contact the University of Missouri Research Participant Advocacy by calling 888-280-5002 (a free call) or emailing MUResearchRPA@ missouri.edu. 
To consent to this research and begin the study, press the "Next" button below. 


\section{Appendix I}

\section{Practice Strategies Scale}

The following questions involve your practice strategies and skills. There are no right or wrong answers. Please choose the response that best represents your answer on a scale from 1(Never) to 5 (Very frequently).

\section{Adoption of Systematic Strategies}

1. I can recognize errors while practicing.

2. When I make a mistake, I practice the section where I went wrong slowly.

3. I practice difficult sections over and over again.

4. I learn by playing slowly to start with and then gradually speed up.

5. I mark things on the part to help me when practicing.

6. I practice small sections of the pieces I am learning.

7. I conduct silent practice (i.e., fingering without making sound).

\section{Metronome and Recordings}

8. I record my playing and listen to the recording.

9. I listen to recordings of other advanced musicians.

10. I practice with the metronome.

\section{Organization}

11. I have a set practice routine.

12. I make a list of what has to be practiced.

13. I begin my practice with scales.

14. I begin each practice session with warm-ups.

15 . I begin my practice with etudes.

16. I review what I practiced at the end of my practice session.

17. I can stick to my practice schedule.

\section{Concentration}

18. I find it is easy to concentrate when I practice.

19. Information from my smartphone may distract my attention when practicing.

20. After browsing information from my smartphone, I can immediately reconcentrate on my practice.

21. If others interrupt me when practicing, I can immediately reconcentrate on my practice.

\section{Analytic Strategies}

22. I try to get an overall idea of a piece before I practice it.

23. I am able to identify difficult sections.

24. I analyze the structure of a piece before I learn to play it.

25. I think about the interpretation of the piece before I start practicing it. 
26. I work things out just by looking at the music and not playing (i.e., mental practice).

27. I analyze the differences of recordings between my performance and other musicians.

\section{Correction of Errors}

28. I stop and correct wrong notes before moving ahead with my practice.

29. I mark my mistakes to help correct them in the future.

30. I can correct errors immediately without the instructor having to mention them. 


\section{Appendix J}

Practice Motivation Scale

The following questions involve your practice attitudes and beliefs. Again, there are no right or wrong answers. Please choose the response that best represents your answer on a scale from 1 (Strongly disagree) to 5 (Strongly agree).

\section{Extrinsic Motivation: Approach Success}

1. I practice my instrument because I want my teacher to think that I am a good musician.

2. I practice my instrument because I want to receive high grades from my teacher.

\section{Extrinsic Motivation: Avoid Failure}

3. I practice my instrument because I do not want to receive criticism from my teacher.

4. I practice my instrument because I do not want my teacher to think that I am a poor student.

\section{Intrinsic Motivation: Growth}

5. I practice my instrument because the skills that I develop are really interesting to me.

6. I practice my instrument because I enjoy accomplishing personal goals.

7. I enjoy practicing my instrument because it allows me to express myself.

8. I practice my instrument because I enjoy a challenge.

9. I enjoy practicing because I like solving problems. 


\section{Appendix K}

\section{Demographic Items}

1. I identify as:
○ Male
- Female
○ Non-binary/third gender
- Prefer not to respond

2. What is your race/ethnicity?
○ White
- Black or African American
- Asian or Pacific Islander
- Hispanic or Latino
- Native American or American Indian
o Other

3. What degree are you studying for?
- Associate Degree
- Bachelor's Degree
- Master's Degree
○ Doctorate Degree

4. What is your age?

5. What is your major?

$\begin{array}{ll}\circ & \text { Conducting } \\ \bigcirc & \text { Composition } \\ \circ & \text { Music Education } \\ \circ & \text { Music History } \\ \circ & \text { Music Performance } \\ \circ & \text { Music Theory } \\ \circ & \text { Music Therapy } \\ \circ & \text { Other }\end{array}$

6. What is your primary instrument?
- Flute
- Oboe
- Clarinet
- Bassoon
- Saxophone
○ Trumpet 


$\begin{array}{ll}\circ & \text { Horn } \\ \circ & \text { Trombone } \\ \circ & \text { Euphonium } \\ \circ & \text { Tuba } \\ \circ & \text { Percussion } \\ \circ & \text { Piano } \\ \circ & \text { Violin } \\ \circ & \text { Viola } \\ \circ & \text { Cello } \\ \circ & \text { Double Bass } \\ \circ & \text { Guitar } \\ \circ & \text { Other }\end{array}$

7. At what age did you begin learning your instrument?

8. Including the current year, how many years have you played your primary instrument?

9. On average, how many hours a week do you practice?

10. On average, how many hours a week do you intend to practice?

11. Where do you learn practice strategies during your college studies? (Mark all that apply)

○ Instructors

- Parents

O Peers

○ Self-exploration (e.g., books, research articles, workshops, concerts)

- Social Media Platform (e.g., Facebook, YouTube, TikTok, Twitter, Instagram) 


\section{VITA}

Yue Liu was born in China. She earned a Bachelor of Arts degree and a Master of Music degree in music education from the Central China Normal University in 2014 and 2017, respectively. She began pursuing her $\mathrm{PhD}$ at the University of Missouri-Columbia (USA) in 2017 and will receive her $\mathrm{PhD}$ in music education in the spring of 2021. At the University of Missouri, she provided presentations and lessons to introduce traditional Chinese instruments, operas, and musical ensembles.

Ms. Liu has presented music education research at state and national venues in both the United States and China. Recent presentations have included Missouri Music Educators Association Conference $(2019,2020)$. Her research has been recommended to publish in Research Studies in Music Education. Her research interests include instrumental practice strategies, instrumental learning motivation, preservice teacher preparation. 